\title{
The Impact of Advertising Regulation on Industry The Cigarette Advertising Ban of 1971
}

\author{
By SHI QI*
}

\begin{abstract}
This paper develops and estimates a dynamic oligopoly model of advertising in the cigarette industry. With this estimated model, I evaluate the impact of the $19^{71} 1 \mathrm{TV} /$ Radio advertising ban on the cigarette industry. A puzzling fact about this ban is that, while industry advertising spending decreased sharply immediately following its passage, spending then recovered and actually exceeded its pre-ban level within five years. While simple static models cannot account for such a turn of events, the rich dynamic model developed in this paper can. This paper exploits previously confidential micro data, now made public through tobacco litigation. In addition, the paper uses a new concept of Oblivious Equilibrium to handle intractable state space and accelerate equilibrium computation.
\end{abstract}

JEL: L13, L25, L51, M37

Keywords: Oligopoly, Industry Regulation, Market Structure, Advertising Dynamics

Economists have long had a keen interest in understanding the role of advertising in the cigarette industry. Writing on the topic in the Journal of Political Economy, Telser (1962) noted that "the cigarette industry has become the traditional example of an industry in which advertising...becomes the main competitive weapon by which oligopolists seek to increase their relative shares." The industry continues to be an example in the more recent economics literature, such as that of Doraszelski and Markovich (2005), and Farr, Tremblay, and Tremblay (2001). Policy makers have also been long interested in cigarette advertising. In 1971, all television and radio cigarette adverting was banned in the United States. More recently, Congress has discussed proposals to further increase advertising restrictions (see Martin (2007)).

This paper develops and estimates a dynamic oligopoly model of advertising in the cigarette industry. Using this estimated model, I then evaluate the impact of the advertising ban on the cigarette industry.

To explain the benefits of using a rich dynamic model, it is useful to consider what happens in a simple static benchmark model. Consider a symmetric oligopolistic industry. The only decision firms make is how much to invest in advertising. Suppose industry demand is perfectly inelastic, such that advertising spending can only shift market share around, but not increase total demand. If advertising is completely banned in this model, it is a windfall to industry. Each firm's sales stay the same in the symmetric oligopoly, but now each firm saves on advertising expenditures. The ban, in effect, helps the industry out of a "Prisoners' Dilemma" situation. This point is well understood theoretically (see Friedman (1983)). Empirically, predictions from this model hold up well in the years immediately following the ban. Advertising expenditures fell sharply in 1971, as aggregate spending declined by $25 \%$. Profits rose as stock returns for the major tobacco companies reached abnormal heights right after the ban (see Mitchell and Mulherin (1988)). Meanwhile, industry demand was inelastic as aggregate sales remained unchanged (see discussion later). However, things began changing within about five years, when advertising spending began to recover and even exceed pre-ban levels.

My model differs from this simple model in four crucial ways, and is therefore able to account for the observed outcomes. First, the regulation was not an outright ban on all advertising, but rather a limit on only one kind of advertising, namely TV/Radio advertising. Other types of advertising, such as in magazines or billboards, were still allowed. Before the ban, a vast majority of industry advertising dollars were spent on TV and radio. According to revealed preferences, TV and radio were the most effective means of delivering the industry's advertising messages. Consequently, the ban made advertising technology less efficient from firms' perspective. Therefore, such a regulation makes it possible for a firm to spend more rather than less on advertising if it wants to hold constant the level of advertising results it achieves.

Second, my model takes into account the dynamic impacts of the policy. In particular, this model treats advertising spending as an investment that builds up a firm's reputation or produces a stock of firm goodwill among consumers ${ }^{1}$. A firm's advertising behavior depends on the efficiency of advertising technology and the goodwill stocks of the firm and its rivals. Goodwill stocks depreciate with time. Immediately following the ban,

\footnotetext{
* I am indebted to my advisor Tom Holmes for his continuous encouragement and support. I am very grateful to Erzo Luttmer and Jim Schmitz for their invaluable comments. I also benefited from the participants of the Applied Micro Workshop at the University of Minnesota. All errors are mine. Mailing Address: Department of Economics, Florida State University. 113 Collegiate Loop, Bellamy 288, Tallahassee FL 32306-2180. Email: sqi@fsu.edu.

${ }^{1}$ This paper treats advertising as "persuasive" rather than "informative." See discussion on informative versus persuasive advertising in Bagwell (2002).
} 
goodwill stocks changed very little, so only the drop in advertising efficiency affected firms' advertising decisions. This caused advertising spending to fall in the short run. In the long term, because firms spent less on inefficient advertising media, goodwill stocks gradually declined through depreciation. A firm's goodwill stock gain increases its own market share and decreases rivals' market shares. For this reason, a reduction of goodwill stocks throughout the industry, especially the reduction of rival firms' stocks, caused the return to advertising to go up. Therefore, aggregate advertising spending eventually recovered and even exceeded pre-ban levels ${ }^{2}$.

Third, my model takes into account firm heterogeneity. In the simple model, all symmetric firms fare the same both before and after the ban. Fixing the number of firms, the simple model suggests that the ban has no impact on the evolution of market structure. However, in the cigarette industry, firms vary greatly in reputations or goodwill stocks. My model considers the policy's differential impacts on firms with different goodwill stocks. Specifically, it studies the effects of the ban on the evolution of industry market share distribution. In addition, it analyzes the differential impacts on firms' advertising spending and profitability. I find that firms with large market shares benefited from the advertising ban, while firms with small market shares suffered from it ${ }^{3}$.

Fourth, my model allows for an alternative explanation for the puzzling aggregate spending pattern observed in the data. In particular, the recovery and long-run increase in aggregate advertising spending can be explained by industry-wide learning about alternative advertising possibilities following the ban. As TV and radio advertisements became unavailable, the industry was forced to explore new tricks and techniques of advertising, such as in-store promotions. These new developments in advertising technology could potentially improve advertising effectiveness, thus leading firms to spend more on advertising. Although industry learning did contribute to the recovery of aggregate advertising spending, my findings suggest that it was not a major factor behind the recovery.

Incorporating these four ingredients, I use a dynamic oligopoly competition model in the tradition of Ericson and Pakes (1995). In this model, firms compete through advertising. The state variables are firms' goodwill stocks, and the equilibrium is a Markov Perfect Equilibrium (MPE). To estimate model parameters, I use the concept of Oblivious Equilibrium (OE) recently developed by Weintraub, Benkard, and van Roy (2007c). This equilibrium concept closely approximates the MPE in Ericson and Pakes (1995) type models under fairly general assumptions. In contrast to MPE, the $\mathrm{OE}$ concept greatly reduces state space by ignoring dynamic strategic interactions among firms, and therefore significantly accelerates equilibrium computation ${ }^{4}$.

This paper exploits novel micro data. The Federal Trade Commission (FTC) required cigarette manufacturers to submit detailed annual reports at the brand level of sales and advertising expenses. The data remained confidential, and only aggregate statistics were disclosed by the FTC. (Most studies use this aggregate data to study the effects of the ban.) As part of the tobacco lawsuit filed by the state of Minnesota, the micro data has been made public. This paper is the first to use this micro data to evaluate the impact of the 1971 ban.

Before estimating the model, I first examine some of the qualitative patterns in the data. As noted, the aggregate data exhibits a clear pattern: there are vast swings in total industry advertising, but no changes in industry sales. In fact, it is impossible to see any connection between the advertising ban and aggregate sales. However, the micro data reveals a connection between the policy and brand-level sales. In particular, before the ban, a high correlation exists between advertising spending and sales growth at the brand level. But in the periods after the ban, this correlation deteriorates dramatically. This pattern in the data helps pin down the structural parameter of the model relating to advertising efficiency.

From the structural estimation, I find that measured advertising efficiency fell by $50 \%$ at the onset of the ban. On account of subsequent industry-wide learning, efficiency did recover, but even years later was still $20 \%$ below its pre-ban level. In addition, the structural parameter estimates allow for a factor decomposition of aggregate advertising spending recovery following the ban. This decomposition reveals that industry learning contributed to less than $30 \%$ of the aggregate spending increase following the ban. Therefore, industry dynamics were the main driving force behind the aggregate spending recovery. Furthermore, a subsequent counterfactual analysis finds that because of the ban, the industry had a higher fraction of small firms. The ban also caused large share firms to advertise more and gain in market share and profitability; and small share firms to advertise less and lose in market share and profitability.

\footnotetext{
${ }^{2}$ See Mathematical Appendix for a simple myopic example illustrating this intuition.

${ }^{3}$ Despite the possibility that the advertising ban might be beneficial to the large cigarette manufacturers, the major cigarette companies lobbied fiercely against any additional advertising restriction. Possibly fearing a "domino's effect" that would eventually lead the government to prohibit cigarette smoking as a whole.

${ }^{4}$ New developments in econometric methods, such as those of Bajari, Benkard, and Levin (2007), make it possible to estimate the model parameters without computing an equilibrium. However, for counterfactual experiments, this paper still needs to rely on the computation of equilibria under different market environments. This makes Oblivious Equilibrium an attractive alternative approach.
} 


\section{A. Related Literature}

This paper is closely related to Roberts and Samuelson (1988), who also estimate a dynamic structural model of oligopoly advertising competition in the cigarette industry. Just like in their paper, firms are assumed to invest in advertising to build goodwill stocks that carry over into future periods. The papers differ in three key ways. First, my paper is primarily interested in the impact of the 1971 advertising ban, which was not considered by Roberts and Samuelson (1988). Second, while all competitive effects of advertising beyond two periods are summarized by a constant in Roberts and Samuelson (1988), new developments in the I.O. literature allows my model to have a richer and more flexible parameterization. Third, the advertising data used in this paper is more reliable since all advertising expenditures were reported directly by the tobacco companies. The data in the earlier paper was provided by a third party media monitoring agency, which did not take into account advertising expenditures in certain media (such as newspaper).

Eckard (1991) is a descriptive paper that studies the effect of the cigarette advertising ban. In particular, Eckard (1991) uses the Herfindahl index to document an increase in market concentration following the 1971 ban. This is consistent with the findings of my paper. My modeling closely follows that of Doraszelski and Markovich (2005). They show theoretically that it is possible for an industry with primarily goodwill advertising to attain an asymmetric outcome when advertising is restricted. This paper provides an empirical basis for their theory by showing that a few large brands gain market shares at the expenses of a large fraction of smaller brands under such situations.

\section{B. Background on the Advertising Ban}

In the late 1960s, a series of regulations targeted the cigarette industry. The key event that initiated these regulations was the publication of the United States Surgeon General's 1964 report. This report found that lung cancer and chronic bronchitis were causally related to cigarette smoking, confirming the suspicion of cigarette smoking's detrimental effects. The initial set of regulations included the requirement of health warning labels on all cigarette packages and the requirement that all cigarette companies file annual reports to the Federal Trade Commission (FTC) on their operating and marketing activities ${ }^{5}$. These regulations culminated in a cigarette advertising ban, which took effect in 1971.

The Public Health Cigarette Smoking Act was introduced in Congress in 1969, and was ultimately signed into law on April $1^{s t}$, 1970. This act effectively banned all cigarette TV and radio advertising in the United States. The magnitude of the impact this act had on cigarette advertising was unparalleled. By the end of 1960s, TV advertising accounted for more than $80 \%$ of the total advertising budgets in the industry. Other forms of advertising, however, such as newspaper, magazine and billboard advertising, were not prohibited by the legislation. The Public Health Cigarette Smoking Act came into force on January $2^{\text {nd }}$, 1971 (a compromise to allow broadcasters to air commercials on New Year's Day 1971). The last commercial ever aired was from the then newly introduced brand, Virginia Slim. This act remains in effect to this day.

\section{Major Assumptions}

In this subsection, I discuss a few important features of the cigarette industry that I incorporate into the model. First, firms in the cigarette industry only compete through advertising. This assumption follows a long tradition in the economic literature. As mentioned above, Telser (1962) was early in recognizing the importance of advertising competition in the cigarette industry. The literature make this assumption for two reasons. First, it is technically easier to focus on one strategic variable rather than two. Second, the cigarette industry is remarkable for its absence of unilateral price moves. There is no history of price wars and prices have remained constant to an extraordinary degree. In fact, in a Pricing Policy report ${ }^{6}$ dated September $28^{t h}, 1976$, Philip Morris addressed its pricing policy on the criteria that it "must be valid on industry-wide grounds." It further stressed that "one reason for seeking a pricing basis that works for the entire industry, rather than for one company, is that competition in our industry is centered about marketing practices."

Second, I assume that advertising has no effect on aggregate demand, but rather shifts its distribution across firms. As we will see, aggregate industry data supports this view. Aggregate advertising spending changed dramatically after the TV/Radio advertising ban, initially declining sharply and then recovering and exceeding pre-ban levels within 5 years. During this period, however, aggregate industry sales stayed on trend and changed very little. In addition, this assumption is consistent with findings from a string of health and marketing studies. These studies

\footnotetext{
${ }^{5}$ These reports included data on sales, advertising, and brand entry and exit. These data were highly confidential. I have collected this dataset for use in this paper.

${ }^{6}$ Obtained from Minnesota Tobacco Document Depository. Serial No. 2023769635:2023769655.
} 
analyze the impact of advertising restrictions on the size of the smoking population. Duffy (1996) provides a comprehensive survey of this literature, and shows that almost all surveyed studies found no significant effects of advertising on aggregate demand ${ }^{7}$.

Finally, this paper uses brand rather than company as the primary unit of analysis. A company, such as Philip Morris, owns multiple brands, such as Marlboro and Benson \& Hedges. Each brand has a distinct trademark specifically designed for the purpose of marketing. The annual advertising reviews prepared by the William Esty Company, an advertising agency for R.J. Reynolds, reveal that most advertising contracts signed between cigarette companies and advertising agencies were for specific brand names. This annual review also implies that advertising decisions were made by brand marketing executives. Brand managers can coordinate their marketing strategies to achieve a better overall outcome for the company. In the model, however, I assume that brand managers make advertising decisions without coordinating with others in the same company. This is a technical simplification, which improves tractability in model analysis by ignoring the strategic interdependence among brands within the same company. The IO literature recognizes that coordination within a multi-divisional organization may not be perfect (see Alonso, Dessein, and Matouschek (2007)). This paper assumes the extreme case whereby decisions are completely decentralized to the brand level. (In future work, I expect to incorporate some degree of coordination across brands within the same company.)

The organization of this paper is as follows: Section 2 details the dynamic model with heterogeneous brands. Section 3 summaries the data. Section 4 details the estimation procedure and discusses estimation results. Section 5 provides the results of counterfactual experiments. Section 6 shows that results are robust with respect to the number of dominant brands. Section 7 concludes.

\section{Model}

This section introduces a general dynamic advertising oligopoly model with heterogeneous brands, defines a Markov Perfect Equilibrium (MPE), and introduces the Oblivious Equilibrium concept that approximates MPE.

\section{A. Model Setup}

Consider a market with countably many potential firms. Refer to each firm as a "brand." Index brands by $j \in J$, where $J$ is the set $\{1,2,3, \ldots, \infty\}$. The industry evolves over discrete time periods and an infinite horizon. I index time periods by $t \in\{0,1,2, \ldots, \infty\}$. For the purposes of the empirical analysis, a time period is assumed to be one year. In each period, a finite subset of brands $J_{t} \subset J$ is actively producing. Refer to brands in $J_{t}$ as active brands. Brand label $j$ remains constant for the same brand across time periods.

Brand heterogeneity is reflected through brand states. The brand specific state is the brand's reputation or goodwill stock, denoted by $s_{j t}$. For any period, for all active brands in that period $\left(j \in J_{t}\right), s_{j t} \geq 0$. Define the industry state $s_{t}$ to be a vector of all active brands' goodwill stocks. Denote $s_{-j, t}$ to be the vector of all active brands' goodwill stocks except for brand $j$.

Let $A_{j t}$ be the advertising activity of an active brand $j$ in period $t$. Each active brand's advertising activity leads to an increase in its goodwill stock. The relationship between $A$ and goodwill stock $s$ is given by:

$$
s_{j, t+1}=\max \left\{0, \delta s_{j t}+\psi\left(A_{j, t} \mid \theta_{t}\right)+\varepsilon_{j, t+1}\right\}
$$

Function $\psi$ is the goodwill production function. This function captures the impact of advertising activity at time $t$ on future goodwill stock. I assume that $\psi(0)=0$, and $\psi$ is non-decreasing and non-convex in $A$.

The advertising efficiency parameter is denoted by $\theta_{t}$, which measures how many units of goodwill stock are produced from a unit of advertising activity $A$. Function $\psi$ changes from period to period due to the possible changes in $\theta_{t}$. I assume that, for any given $A, \psi$ is increasing in $\theta$. In other words, the higher $\theta$, the higher the goodwill stock production. Efficiency $\theta$ drops due to the advertising ban.

In addition, I add a forecast error term $\varepsilon_{j, t+1}$. I assume that $\varepsilon_{j, t+1}$ is drawn from a common distribution $\Phi(\cdot)$, and is i.i.d. across time periods and brands. The term $\varepsilon_{j, t+1}$ reflects uncertain aspects in the outcome of advertising investments. Uncertainty may arise due to idiosyncrasies in the quality of advertising messages. Furthermore, the depreciation rate of goodwill stock is denoted by $\delta \in[0,1]$.

The advertising expenditure for producing $A_{j t}$ is $C\left(A_{j t}, \nu_{j t}\right)$. Each active brand draws a private cost shock $\nu_{j t}$ from a common distribution $\Gamma(\cdot)$. The shock $\nu_{j t}$ is i.i.d. across time periods and brands. This captures the idiosyncrasies in brand advertising decisions that are not directly observed in data. The shock $\nu_{j t}$ is brand $j$ 's private information. Brand $j$ observes $\nu_{j t}$ before it makes the investment decision in time period $t$. Since the $\nu \mathrm{s}$

\footnotetext{
${ }^{7}$ Many studies, as early as Hamilton (1972) and as recent as Farr, Tremblay, and Tremblay (2001), also consider the effect of advertising on price elasticities of demand.
} 
are private information, brand $j$ does not take into account any other brands' investment cost shocks in making its advertising decisions.

Assume that brands only engage in advertising competition. All brands are price takers, with perfect foresight of the exogenous series of industry prices $\left\{P_{t}\right\}$. Denote the total industry demand of cigarettes (industry market size) in period $t$ as $M_{t}$. I assume that advertising does not change overall industry demand. Therefore, the industry market size $M_{t}$ is exogenous. Market size $M_{t}$ is measured in units of cigarettes sold. Brands have prefect foresight on market size over time.

In each period, all active brands compete for market share, and each earns profits. I use $\pi_{t}\left(s_{j t}, s_{-j, t}\right)$ to denote a brand $j$ 's single period expected profit. The profit function $\pi$ changes from period to period due to changes in industry price $\left\{P_{t}\right\}$ and overall market size $\left\{M_{t}\right\}$. Profit $\pi_{t}$ is increasing in a brand's own goodwill stock and is decreasing in all rivals' goodwill stocks. I further assume that $\pi_{t}$ is concave in $s$. A brand $j$ 's total pay-off in period $t$ is the spot market profits subtracted by the advertising expenditure $C(A, \nu)$ :

$$
h\left(s_{j t}, s_{t}, A_{j t}, \nu_{j t}\right):=\pi_{t}\left(s_{j t}, s_{-j, t}\right)-C\left(A_{j t}, \nu_{j t}\right)
$$

Brand entries and exits are not strategic in this model, but are instead modeled in a mechanical way. This is a technical simplification, and I will address how results may change due to strategic entry and exit in future work. In the Data section, however, I present some evidence that entering and exiting brands were exceptionally small in size and had very little strategic impact on the overall industry ${ }^{8}$. In each period, all active brands are faced with a fixed exit probability $\phi \in[0,1]$. Once a brand exits, it exits the industry forever. In addition, $\lambda$ new brands enter the industry ${ }^{9}$. All new brands enter the market with a random goodwill stock level $s^{e}=\max \{0, \varepsilon\}$. I further assume that the number of active brand is constant overtime. Denote this constant ${ }^{10} \chi$, then $\phi \times \chi=\lambda$.

From equation (1), I can derive an active brand's transition probability from a goodwill stock $s$ in period $t$ to a goodwill stock $s^{\prime}$ in period $t+1$ conditional on the brand not exiting at the end of period $t$. Denote this transition probability $\tilde{\rho}_{t}\left(s^{\prime} \mid s, A\right)$. Then, the unconditional Markov transition probability is the conditional transition probability multiplied by the probability that the brand will continue in period $t+1$ :

$$
\rho_{t}\left(s^{\prime} \mid s, A\right)=(1-\phi) \tilde{\rho}_{t}\left(s^{\prime} \mid s, A\right)
$$

For an entrant brand the transition $\rho_{t}$ is the probability of getting to goodwill stock level $\varepsilon$. Then, the industry state vector $s_{t}$ has a Markov transition density that is the product of individual probabilities given the vector of actions $\mathcal{A}_{t}=\left\{A_{j t}\right\}$ for all $j \in J_{t}$ :

$$
\rho_{t}\left(s^{\prime} \mid s, \mathcal{A}_{t}\right)=\prod_{j=1}^{J_{t}} \rho_{t}\left(s_{j}^{\prime} \mid s_{j}, A_{j t}\right)
$$

Each brand aims to maximize its expected net present value. The discount factor $\beta \in(0,1)$ is assumed to be constant over all time periods. The timing in each period is as follows:

1) Each active brand observes the brand specific cost shock and then makes its investment decision.

2) Active brands compete for market shares and receive profits.

3) Active brands exit randomly according to $\phi$, and exiting brands exit the industry permanently.

4) $\lambda$ new brands enter, and each receives an initial goodwill stock $s^{e}$.

5) Investment outcomes are determined, goodwill stocks are updated, and the industry takes on a new state $s_{t+1}$.

\section{B. Equilibrium Concept}

In each time period, each active brand $j$ makes the advertising investment decision $A_{j t}$ given the relevant state variables $(s, \nu)$. Denote a brand $j$ 's strategy $\sigma_{j}$, which maps the current state into the action space, $\sigma_{j t}\left(s_{t}, \nu_{j t}\right)=$ $A_{j t}$. A strategy profile $\sigma_{t}$ is a vector of the decision rules for all active brands in period $t$. Then, the expected

\footnotetext{
${ }^{8}$ I need entry and exit in this model. Without entry and exit, for certain parameters, the model converges to an extreme asymmetric outcome with one brand monopolizing almost the whole industry.

${ }^{9}$ Suppose that $J_{t}=\left\{j_{1, t}, j_{2, t}, \ldots, j_{N_{t}, t}\right\} \subset J$, then the set of indices of new brands in $t+1$ is $\left\{j_{N_{t}, t}+1, j_{N_{t}, t}+2, \ldots, j_{N_{t}, t}+\lambda\right\}$.

${ }^{10}$ Alternatively, I can use a random number of entrants and a random exit rate with means specified by $\lambda$ and $\phi$. This specification does not have a big impact on results.
} 
present discounted value of brand $j$, given that its competitors follow a common strategy $\tilde{\sigma}$, and the brand itself follows a strategy $\sigma_{j}$, is:

$$
V_{j t}\left(s, \nu \mid \sigma_{j}, \tilde{\sigma}\right)=h\left(s_{j}, s, \sigma_{j}(s, \nu), \nu\right)+\beta \int_{s^{\prime}} \int_{\nu^{\prime}} W_{j, t+1}\left(s^{\prime}, \nu^{\prime} \mid \sigma_{j}\right) d \rho_{t}\left(s^{\prime} \mid s, \sigma_{j}(s, \nu)\right) d \Gamma\left(\nu^{\prime}\right)
$$

where:

$$
W_{j, t+1}\left(s^{\prime}, \nu^{\prime} \mid \sigma_{j}\right)=\int_{s_{-j}^{\prime}} V_{j, t+1}\left(s^{\prime}, \nu^{\prime} \mid \sigma_{j}, \tilde{\sigma}\right) d \rho_{t}\left(s_{-j}^{\prime} \mid s_{-j}, \sigma_{-j}\left(s_{-j}, \nu_{-j}\right)\right) \Gamma\left(\nu_{-j}\right)
$$

Notice that value function is not stationary, because $P_{t}, M_{t}$, and advertising efficiency $\theta_{t}$ are changing over time. A Markov Perfect Equilibrium for the dynamic advertising game is a strategy profile $\sigma^{*}$, such that no active brand can make profitable deviation from $\sigma_{j}^{*}$ in any subgame that starts at some state $s$.

DEFINITION 1: A Markov Perfect Equilibrium is a Markov strategy profile $\sigma^{*}$, such that for any active brand $j$ and all $t$, for any industry state $s$, and for any given shock $\nu$ :

$$
V_{j t}\left(s, \nu \mid \sigma_{j}^{*}, \sigma^{*}\right) \geq V_{j t}\left(s, \nu \mid \sigma_{j}, \sigma^{*}\right)
$$

for any alternative strategy $\sigma_{j}$ by brand $j$.

This paper considers only a pure strategy symmetric Markov Perfect Equilibrium.. The equilibrium concept here is closely related to the ones considered by Doraszelski and Satterthwaite (2003), who established the existence of equilibrium in pure strategies ${ }^{11}$.

In using dynamic programming to solve this model, it is clear that large numbers of industry states would make the model intractable for practical purposes. To avoid the curse of dimensionality, I apply an alternative approach that I discuss next.

\section{Oblivious Equilibrium}

In this section, I lay out a method of approximating Markov Perfect Equilibrium based on the notion of Oblivious Equilibrium (OE) ${ }^{12}$. Weintraub, Benkard, and van Roy (2007c) first introduced this equilibrium concept, which is based on the idea that simultaneous changes in an individual agent's state can be averaged out when there are a large number of firms. In this sense, from an initial state, the industry state roughly follows a deterministic path. It is therefore possible for each fringe agent to make near optimal decisions based on the agent's own state and the deterministic average industry state.

In the cigarette industry, there are a few well-established brands, such as Camel and Marlboro. These brands' market shares can well exceed $10 \%$, and their strategic actions may affect all other brands' action. Therefore, I also consider the possibility of dominant brands. As introduced in Weintraub, Benkard, and van Roy (2007b), every brand, under the dominant-brand environment, keeps track of its own states and the states of the dominant brands. Only dominant brands' actions can affect the trajectory of industry states.

In a non-stationary environment, such as the one presented in this paper, it becomes possible to trace backward period by period net present value with the non-stationary partial OE value function. This is made possible by assuming that the industry attains a stationary oblivious equilibrium in the very distant future. I can therefore numerically simulate industry evolution for the relevant time periods. The equilibrium concept I use here is Weintraub, Benkard, and van Roy (2007b)'s concept of Non-stationary Partial Oblivious Equilibrium (NPOE).

Let $I=\left\{i_{1}, i_{2}, \ldots, i_{n}\right\}$ be the set of indices associated with dominant brands. The identities of the $n$ dominant brands do not change over time. Let $y_{t}$ be a vector of goodwill stocks for the dominant brands at time $t$, where $y_{t}=\left(s_{i_{1} t}, \ldots, s_{i_{n} t}\right)$. If during the period of analysis, any of the dominant brands exit the industry, it disappears from the industry forever. All other brands in the market are called fringe brands. All newly entering brands are fringe brands. Denote the vector of goodwill stocks for active fringe brands $z_{t}$, then $z_{t}$ is a vector of all $s_{j t}$ for $j \in J_{t}$ and $j \notin I$. In Markov Perfect Equilibrium, the industry state is $s_{t}=\left(y_{t}, z_{t}\right)$.

To make equilibrium computation feasible, NPOE assumes that fringe brands' actions do not affect other brands' decisions. Therefore, instead of keeping track of $z_{t}$, brands make a prediction of fringe brand states based on

\footnotetext{
${ }^{11}$ Due to differences in model setup, the results from Doraszelski and Satterthwaite (2003) cannot be directly applied to my paper. However, this does not affect the computational results.

${ }^{12}$ For extensive details on this equilibrium concept, and computation methods, please refer to Weintraub, Benkard, and van Roy (2007a).
} 
averages. Because brands keep track of dominant brands' states, this prediction will depend on the evolution of dominant brand states. Since there is no aggregate uncertainty, and if the number of fringe brands is large, brands should be able to accurately predict fringe brands' states for any given period based on entire history of dominant brands' states. To keep computation practical, I assume brands predict the fringe brands' states based on a finite set of statistics $w_{t}$ that depends on the entire evolution of dominant brands' states. The term $w_{t}$ is specified as follows ${ }^{13}: w_{t}(1)=y_{t}, w_{t+1}(2)=\alpha y_{t}+(1-\alpha) w_{t}$, and $w_{0}(2)=0$.

Using this motivation, NPOE restricts a brand's optimal decisions to depend only on the brand's own states, the time period, the current state of dominant brands, and the finite set of statistics $w_{t}$. If a brand uses strategy $\sigma_{t}$ in time period $t$, then brand $j$ invests $\sigma_{t}\left(s_{j t}, \nu_{j t}, \imath_{j}, y_{t}, w_{t}\right)$, where $\imath_{j}$ is a binary indicator function. If brand $j$ is a dominant brand then $\imath_{j}=1$, and $\imath_{j}=0$ otherwise.

In NPOE, the average industry states consist of the expected states for all fringe brands. Suppose that the initial time period is $t=0$, the initial dominant brand state is $y_{0}$ and the initial fringe state is $z_{0}$. I denote ${ }^{14}$ $\tilde{z}_{\left(\sigma, y_{0}, z_{0}\right), t}(w)=E_{\left(\sigma, y_{0}, z_{0}\right)}\left[z_{t} \mid w_{t}=w\right]$. Conditional on the evolution of dominant brands' states, the fringe brands' expected states evolve according to a deterministic trajectory. Therefore, if a fringe brand deviates from $\sigma, \tilde{z}$ does not change. However, if a dominant brand $i$ deviates from the strategy $\sigma$, and uses $\sigma^{\prime}$, then $\tilde{z}$ is affected. Denote this affected path $\tilde{z}_{\left(i, \sigma^{\prime}, \sigma, y_{0}, z_{0}\right), t}(w)=E_{\left(i, \sigma^{\prime}, \sigma, y_{0}, z_{0}\right)}\left[z_{t} \mid w_{t}=w\right]$. I solve a set of balance equations to obtain $\tilde{z}_{\left(\sigma, y_{0}, z_{0}\right), t}(w)$ and $\tilde{z}_{\left(i, \sigma^{\prime}, \sigma, y_{0}, z_{0}\right), t}(w)$ (see Appendix).

If a dominant brand $j$ uses strategy $\sigma_{j}$ and all other brands following the strategy profile $\tilde{\sigma}$, I can define the value function for the dominant brand $j$ in NPOE in the following fashion:

$$
\begin{aligned}
& \tilde{V}_{j t}\left(s,\left(\imath_{j}=1\right), \nu, w \mid \sigma_{j}, \tilde{\sigma}, y_{0}, z_{0}\right)=h\left(s_{j t}, y_{t}, \tilde{z}_{\left(j, \sigma_{j}, \tilde{\sigma}, y_{0}, z_{0}\right), t}\left(w_{t}\right), \sigma_{j}, \nu\right) \\
& \quad+\beta \int_{s^{\prime}, \nu^{\prime}} \tilde{V}_{j, t+1}\left(s^{\prime},\left(\iota_{j}=1\right), \nu^{\prime}, w \mid \sigma_{j}, \tilde{\sigma}, y_{0}, z_{0}\right) d \tilde{\rho}_{t}\left(s^{\prime} \mid s, \sigma_{j}\right) d \Gamma\left(\nu^{\prime}\right)
\end{aligned}
$$

Note that dominant brand $j$ needs to subtract itself out from dominant state $y$. In addition, because the dominant brand makes a deviation $\sigma_{j t}$ at time $t$, it need to take into account the possible change in expected fringe state $\tilde{z}_{\left(j, \sigma, \tilde{\sigma}, y_{0}, z_{0}\right), k}$ for all $k>t$. Similarly, I can define the value function for a fringe brand $j$ :

$$
\begin{array}{r}
\tilde{V}_{j t}\left(s,(\iota=0), \nu, w \mid \sigma_{j}, \tilde{\sigma}, y_{0}, z_{0}\right)=h\left(s_{j t}, y_{t}, \tilde{z}_{\left(\tilde{\sigma}, y_{0}, z_{0}\right), t}\left(w_{t}\right), \sigma_{j}, \nu\right) \\
\quad+\beta \int_{s^{\prime}, \nu^{\prime}} \tilde{V}_{j, t+1}\left(s^{\prime},(\iota=0), \nu^{\prime}, w \mid \sigma_{j}, \tilde{\sigma}\right) d \tilde{\rho}_{t}\left(s^{\prime} \mid s, \sigma_{j}\right) d \Gamma\left(\nu^{\prime}\right)
\end{array}
$$

Here, the deviant brand is a fringe brand; hence, the evolution of $\tilde{z}_{\left(\tilde{\sigma}, y_{0}, z_{0}\right), k}$ is not affected.

DEFINITION 2: A non-stationary partial oblivious equilibrium consists of strategy profile $\sigma^{*}$ such that for any type of brand $\imath$, any brand $j$ and any time period $t$, any $w$ :

$$
\tilde{V}_{j t}\left(s, \imath_{j}, \nu, w \mid \sigma_{j}^{*}, \sigma^{*}, y_{0}, z_{0}\right) \geq \tilde{V}_{j t}\left(s, \imath_{j}, \nu, w \mid \sigma_{j}, \sigma^{*}, y_{0}, z_{0}\right)
$$

for any alternative strategy $\sigma_{j}$ by brand $j$ given state $(s, \nu)$.

As can be seen above, instead of keeping track of all active brands' state variables in each period, a given brand is only keeping track of its own state $s_{j}$ and $\nu_{j}$, as well as the dominant brand states $\left\{y_{t}\right\}$. All brands are symmetric given the same state variable; hence $\sigma_{t}(s, \imath, \nu, y, w)$ is the same for every fringe brand. Therefore, when computing the oblivious equilibrium, I only need to compute the optimal strategy function of one fringe brand. This greatly reduces the computational burden.

Notice that the above equilibrium concept converges to the Markov Perfect Equilibrium as defined above when every active brand is a dominant brand. In practice, I estimate the model using Oblivious Equilibrium with no dominant brands, which is a special case of the equilibrium concept described above. Later, I compare the no dominant brand case to cases with one and two dominant brands, and show that results are robust to the number of dominant brands.

\section{Data}

This section describes the data used in this paper, both its source and content. In addition, it provides descriptive statistics on the cigarette industry using this data.

\footnotetext{
${ }^{13}$ In practice, I assume $\alpha=0$, so the predictions only depends on $y_{t}$. I will address the case where $\alpha>0$ in future work.

${ }^{14}$ If there is no dominant brands, $\tilde{z}$ is deterministic.
} 


\section{A. Institutional Background}

This paper uses a unique set of brand-level data. The source of this data is the Minnesota Tobacco Document Depository. The Minnesota Tobacco Document Depository was created after the settlement of Minnesota vs. Philip Morris, et. al. In 1998, the State of Minnesota won a lawsuit against six major U.S. cigarette manufacturers (American Tobacco, Lorillard, R.J. Reynolds, Liggett \& Myers, Brown \& Williamson, and Philip Morris USA) ${ }^{15}$. The U.S. Congress required 5 out of the 6 major companies involved (Liggett \& Myers was excluded due to its small size of less than $3 \%$ market share) to disclose all documents (over 33 million pages) used in the lawsuit's proceedings. Funding was provided to a private company for establishing a depository in Hennepin County, Minnesota, which kept all physical copies of these documents.

The data was specifically collected from Special Report, FTC File No. 662 - No. 802, filed annually by individual cigarette manufacturers to the Federal Trade Commission as required by the Cigarette labeling and Advertising Act described above. The information contained in this dataset remained highly confidential until after the aforementioned lawsuit. Compared with data collected by third party industry monitoring agencies, this data is more accurate. In addition, the data is difficult to obtain, as most reports were hand written in pre-ban years, and with no digital copies. I accessed this archive and examined the handwritten reports. To the best of my knowledge, this paper is the first to use this micro data, especially for the early years, to study the impact of the 1971 advertising ban $^{16}$.

This data contains detailed brand-level annual data of sales and advertising expenditures. Specifically, the data consists of 21 years (1960-1980), with information on units sold, advertising expenditures in various categories, cigarette characteristics and market entry and discontinuation dates for 5 companies and 137 brands. Various other documents from the depository were also used to corroborate the data obtained from the Special Reports.

\section{B. Data Content}

From the reports filed by the five companies included in the depository, a total of 137 brands are included in the data. As mentioned before, a brand is a tradename for marketing cigarette products. Examples of large brands in this industry are Marlboro, Winston, Pall Mall, Salem and Kool. Advertising data are reported at the brand-level, such that individual brands are treated as an independent unit of profit maximization instead of companies ${ }^{17}$.

For all brands, the reports provide information on annual domestic sales. Sales are reported in units of cigarettes sold in the U.S. domestic market (not in dollars). The special reports also provide brand-level advertising expenditures in dollars. There are many different categories of advertising expenditures, such as Television, Newspapers, and Magazines. For the purpose of this paper, I ignore the distinctions between different categories of advertising, and use only the total advertising expenditures by brand. The exclusion of TV/Radio advertising in later years is captured by the change in the advertising efficiency parameter $\theta_{t}$.

In addition, the Special Reports provide information on the introduction and discontinuation years (if available) of a product. Introduction refers to general release into the U.S. domestic market rather than test marketing.

Additional supplementary reports were used to corroborate the Special Reports, since some data were not printed clearly or were missing. The 1960-1965 advertising information was corroborated by Competitive Advertising in the Cigarette Industry, an annual review by the William Esty Company prepared for R.J. Reynolds. It reports many major brands' advertising expenditures in the above-mentioned categories. Sales data were corroborated by Historical Sales Trends in the Cigarette Industry (1925-1990) by J.C. Maxwell, which are widely used by industry economists. This report is published annually by Wachovia Security and reports only product-level sales. The entry and discontinuation years are corroborated by Summary of Competitive Brand Changes Observed Since 1960, published by the Philip Morris USA research department.

All sales data are rounded to the nearest millionth unit, and all advertising expenditure data are rounded to the nearest thousandth dollar. All dollar figures are adjusted for inflation using the Consumer Price Index. Alternative inflation adjustments were computed and yielded no significant changes to the results. A few brands were discontinued only to be reintroduced years later under the same trade name. In this dataset, I consider these as separate brands. Brand introduction year is the second year the first product under a brand was introduced into the market. I choose the second year to avoid the problem presented by brands entering the market late in the year.

\footnotetext{
${ }^{15}$ Historically, six tobacco companies dominated the U.S. domestic market, with over $90 \%$ of the total domestic market share.

${ }^{16}$ The tobacco documents from the depository are mostly used by health advocates and consumer researchers. According to Carter (2007), a total of 173 papers cited documents from the depository or related sources from 1998 to 2007 . To my knowledge, one economic paper, Tan (2006), uses the Special Reports as data source. The author uses the data for 1990-1996. This paper uses data from a different time period (1960-1980), and studies the advertising ban of 1971.

${ }^{17}$ Some brands have various products with different physical attributes, such as Marlboro menthol and Marlboro light. In principle, the analysis could be undertaken at the finer product-level. However, companies reported advertising spending at the product level in only a few instances.
} 
Other reports indicate that brands often enter the market in late November or early December to accommodate the Christmas season. Discontinuation year is the first year in which no product under the brand's trade name is in the market.

Table 1 - Sample Data - Marlboro

\begin{tabular}{|c|c|c|c|c|c|}
\hline \multicolumn{3}{|c|}{$\begin{array}{l}\text { Brand Name: Marlboro } \\
\text { Company: Philip Morris }\end{array}$} & \multicolumn{3}{|c|}{$\begin{array}{l}\text { Entry Year: } 1955 \\
\text { Exit Year: NA } \\
\end{array}$} \\
\hline \multirow[t]{2}{*}{ Year } & Sales & \multicolumn{4}{|c|}{ Advertising } \\
\hline & (Mil. Units) & $\begin{array}{r}\text { Total } \\
(\$ 1 \text { Mil. })\end{array}$ & $\begin{array}{r}\text { TV/Radio } \\
(\$ 1 \text { Mil. })\end{array}$ & $\begin{array}{r}\text { Print } \\
(\$ 1 \text { Mil. })\end{array}$ & $\begin{array}{l}\text { Point of Sale } \\
(\$ 1 \text { Mil. })\end{array}$ \\
\hline 1969 & 44,090 & 102.6 & 76.7 & 22.7 & 3.3 \\
\hline 1970 & 51,370 & 114.7 & 85.2 & 26.4 & 3.1 \\
\hline 1971 & 59,320 & 125.0 & 4.8 & 103.2 & 16.9 \\
\hline 1972 & 69,820 & 130.8 & 0.0 & 118.3 & 12.4 \\
\hline 1973 & 78,831 & 108.8 & 0.0 & 101.3 & 7.5 \\
\hline 1974 & 86,211 & 121.4 & 0.0 & 115.1 & 6.3 \\
\hline \multicolumn{3}{|c|}{$\begin{array}{l}\text { Brand Name: Hit Parade } \\
\text { Company: American Tobacco }\end{array}$} & \multicolumn{3}{|c|}{$\begin{array}{l}\text { Entry Year: } 1958 \\
\text { Exit Year: } 1967\end{array}$} \\
\hline \multirow[t]{2}{*}{ Year } & Sales & & \multicolumn{2}{|c|}{ Advertising } & \\
\hline & (Mil. Units) & $\begin{array}{r}\text { Total } \\
(\$ 1 \text { Mil. })\end{array}$ & $\begin{array}{r}\text { TV/Radio } \\
(\$ 1 \text { Mil. })\end{array}$ & $\begin{array}{r}\text { Print } \\
(\$ 1 \text { Mil. })\end{array}$ & $\begin{array}{l}\text { Point of Sale } \\
\qquad(\$ 1 \text { Mil. })\end{array}$ \\
\hline 1960 & 500 & 0.12 & 0.12 & 0 & 0 \\
\hline 1961 & 200 & 0.09 & 0.09 & 0 & 0 \\
\hline 1962 & 100 & 0.13 & 0.13 & 0 & 0 \\
\hline 1963 & 148 & 0.01 & 0.01 & 0 & 0 \\
\hline 1964 & 87 & 0.00 & 0.00 & 0 & 0 \\
\hline 1965 & 60 & 0.00 & 0.00 & 0 & 0 \\
\hline
\end{tabular}

In Table 1, I present sample data for one large brand (Marlboro) and one small brand (Hit Parade) (each for six years). In particular, the advertising types reported are TV/Radio, Print(newspaper and magazine), and Pointof-Sale (in store) advertising. These categories are summed to the total advertising spending measure used in this study. As one can see from the sample data (Marlboro), brands switched quickly from TV/Radio to other media after the $\operatorname{ban}^{18}$.

\section{Descriptive Evidence}

This subsection provides descriptive statistics for the following: (1) industry trends for sales, prices, and advertising at the aggregate level; (2) trends of sales and advertising for a few large brands; (3) the relationship between advertising and brand-level sales growth; and (4) entry and exit (which turn out not to be quantitatively important).

\section{AgGregate Industry Statistics}

At the aggregate level, the advertising ban had a large impact on industry advertising spending, though unit sales and prices were relatively unchanged following its implementation. These findings support the assumptions that (1) advertising does not change aggregate industry demand, and (2) prices are exogenous (at least these assumptions do not grossly contradict the data).

Figure 1 shows change in total industry advertising spending over the years. Immediately after the ban, total industry advertising spending decreased by $25 \%$ from 1970 to 1971 . Spending remained low for a period of 3-4 years. Starting from the fifth year after the ban, advertising spending started to recover. By 1980, total spending was actually $80 \%$ higher than pre-1970 levels.

Besides advertising spending, other aggregate statistics for the cigarette industry remained relatively unchanged during and after the ban. After the ban, total industry sales continued growing at a pace of $1.5 \%$ annually. This

\footnotetext{
${ }^{18}$ Note that spending on TV/Radio is 0 in 1972 and there is a small amount of advertising in 1971 compared to the previous year. Advertising was allowed on January $1^{\text {st }}$, 1971 (a heavy advertising day with New Years Bowl games) and this can account for the positive advertising in 1971.
} 


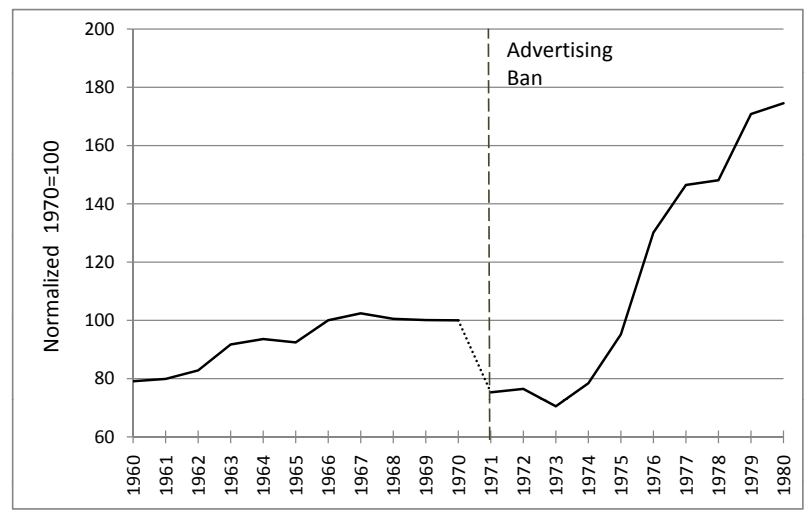

Figure 1. Total Industry Advertising Spending (Normalized $1970=100)$

is well inside the range of past growth rates prior the ban (see Figure 2). One possible explanation for this lack of change in market size is the addictive nature of cigarette smoking. It is precisely because of this relative lack of change, numerous early aggregate industry studies (such as Hamilton (1972)) concluded that the elasticity of demand with respect to advertising is small and insignificant at the aggregate level.

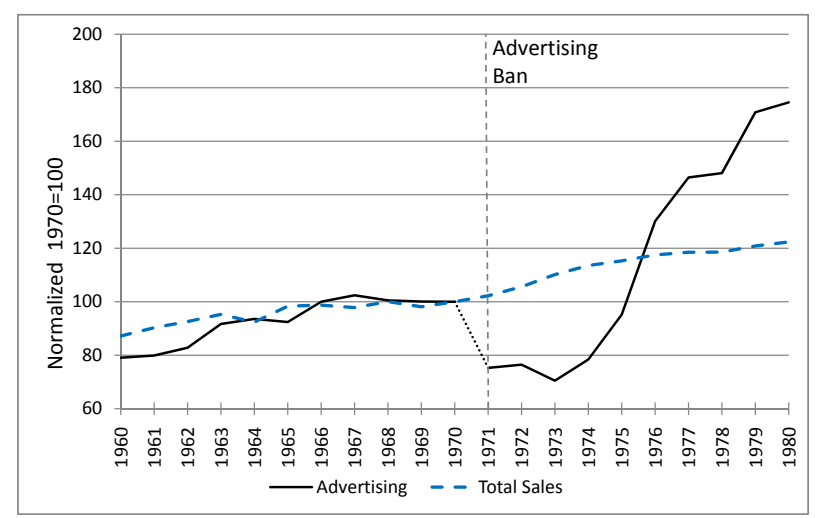

(a) Advertising vs. Sales

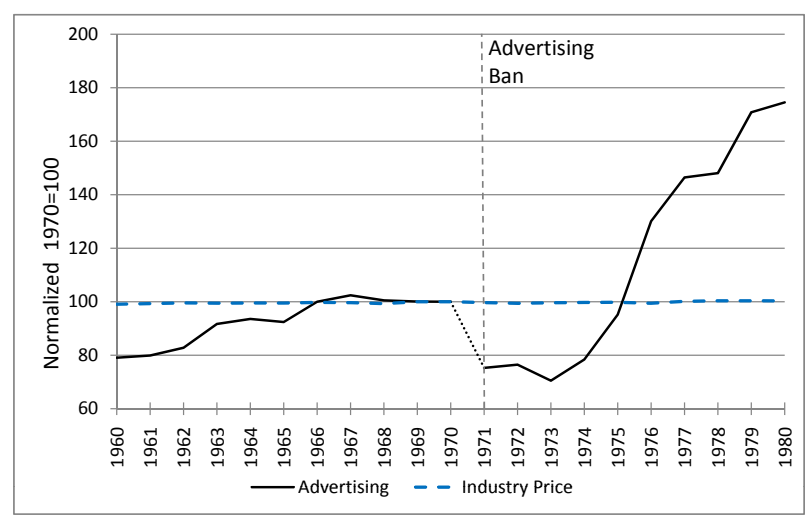

(b) Advertising vs. Price

Figure 2. Industry Advertising Spending vs. Industry Sales and Price (Normalized $1970=100$ )

This paper also reports aggregate prices. The industry price information is from Tobacco Situation and Outlook Report by the U.S. Department of Agriculture: Economic Research Service. I use the mid-year net price per 1000 cigarettes excluding all excise taxes. As mentioned above, the cigarette industry has very little price competition, and prices remained rigid over the period of study. This is evident in the right panel of Figure 2 .

\section{TOP RANKED BRANDS}

Here I show disaggregated trends in sales and advertising expenditures for the five largest brands according to their sales in 1970 (the year before the advertising ban). Evidence from these top brands shows that (1) the effect of the ban on advertising spending occurs mostly within brands rather than across brands; and (2) the model is able to capture brand-level idiosyncrasies.

The five largest brands by sales in 1970 were Winston, Pall Mall, Marlboro, Salem and Kool. As shown in the right panel of Figure 3, after normalizing each of the five brands' sales in 1970 to 100, there were no significant changes in the brands' sales trends. Marlboro and Kool showed large market share gains, Winston and Salem's market shares increased slightly, and Pall Mall experienced a large market share reduction. All these trends were already well established before the advertising ban.

To study the trends in advertising spending, I look at advertising spending per cigarette sold. Note that at the aggregate level, total industry sales were relatively unchanged, so the effect of changes in sales on changes in advertising was small. However, sales fluctuated substantially at the brand level. Looking at advertising spending 


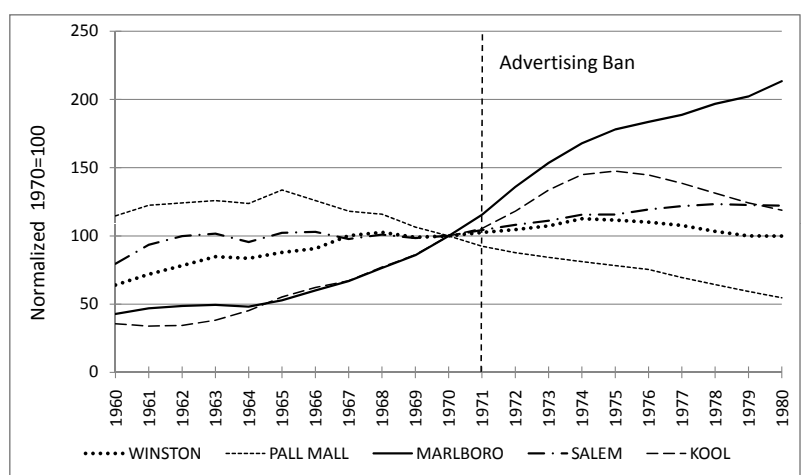

(a) Cigarette Sales

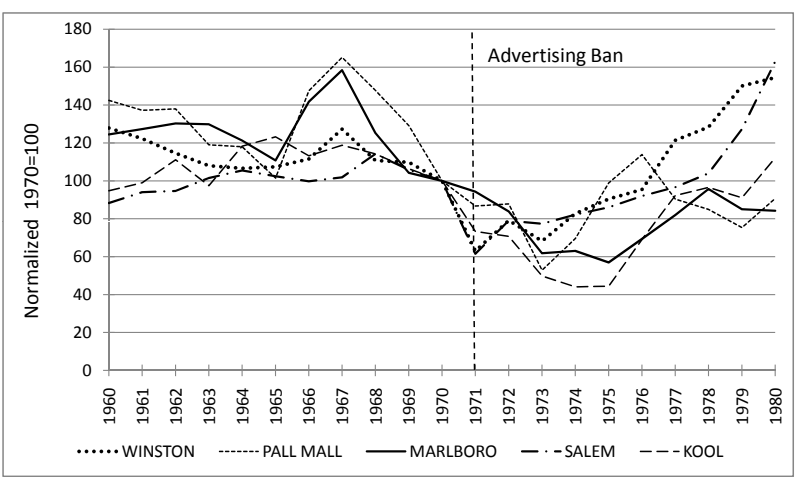

(b) Advertising Per Cigarette Sold

Figure 3. Unit Sales and Advertising Spending Per Unit Sold: Largest 5 Brand by Sales in 1970 (Normalized $1970=100)$

per cigarette sold neutralizes the effect of fluctuation in sales on advertising spending. The right panel of Figure 3 shows these statistics normalized to 100 at the 1970 level. Just like the industry overall, each brand experienced an advertising spending recovery 4-5 years after the ban. This shows that the industry level recovery was not due to changes in brand composition but rather to the recovery of spending of each brand (at least the large ones). For Winston, Salem and Kool, the immediate effect of the advertising ban on brand advertising spending was similar to its effect on aggregate industry spending. Winston and Salem's advertising dropped by $40 \%$, and Kool's by $25 \%$ immediately following the ban.

In addition, large brands demonstrate brand-level idiosyncrasies. Pall Mall's advertising spending per cigarette was drastically cut after 1967, and Marlboro experienced a steady decrease in advertising spending per cigarette after the mid 1960s. These two instances of spending decreases, however, stem from different causes. Pall Mall's sales were decreasing, and a cut in advertising followed. Marlboro experienced large sales growth from the mid1960s to mid-1970s, when Marlboro sales tripled. Although Marlboro's total advertising spending was increasing, the sales increase outpaced the increase in advertising. This translated into a decline in advertising spending per cigarette. All these patterns can potentially be captured by my model ${ }^{19}$. In the case of Pall Mall, the decline of sales can be the result of a large negative goodwill stock draw $\varepsilon$ in the mid-60s, and the decline in advertising per cigarette can be the result of a high advertising cost draw $\nu$. Meanwhile, Marlboro faces exactly the opposite situation. It had a large positive goodwill stock draw $\varepsilon$, and a series of low cost shocks $\nu$.

\section{DESCRIPTIVE REgRESSION}

The previous evidence shows that the advertising ban had relatively little impact on aggregate sales. This subsection uses brand-level data, and shows that advertising spending is correlated with brand-level growth in sales. A descriptive regression relating advertising to brand-level sales growth is specified as follows:

$$
\left[\log \left(S A L E_{j, t+1}\right)-\log \left(S A L E_{j, t}\right)\right]=C O N_{t}+\kappa_{t}\left(\log \left(A D V_{j, t} / S A L E_{j, t}+1\right)\right)+E R R O R_{j, t+1}
$$

Note that $\kappa_{t}$ simply describes the correlation between advertising spending and sales growth, and does not have a structural interpretation. The error term here is similar to the forecast error specified in the structural model.

The coefficients and their standard errors as well as the R-squared are reported in Table 2.

The regression coefficient $\kappa_{t}$ changes significantly before and after the ban. The mean of $\kappa_{t}$ before the ban was 0.558 , and 0.273 after the ban. In Table 2 , notice also that the coefficient $\kappa_{t}$ drops significantly at the onset of the advertising ban, then improves over time in the years following the ban. Despite this improvement, the coefficient never reaches its pre-ban level. This suggests that the effectiveness of advertising never fully recovered. This means that the dramatic increase in advertising spending, which came to exceed pre-ban levels, must come from factors other than advertising technology changes.

\section{ENTRY AND EXIT}

The model incorporates entry and exit in a mechanical way. To alleviate concerns that the lack of strategic entry and exit may significantly alter the results, I show here that entry and exit have only a relatively small impact on the industry as a whole.

\footnotetext{
${ }^{19}$ I do not have persistence in error terms in my model, so the model cannot capture trends. Potentially, I can use an AR1 process to improve this aspect of the model.
} 
TABle 2-Descriptive Regression

\begin{tabular}{|c|cc|cc|c|}
\hline & \multicolumn{2}{|c|}{$\kappa_{t}$} & \multicolumn{2}{c|}{$C O N_{t}$} & $R^{2}$ \\
\hline \multicolumn{7}{|c|}{ Coeff } & s.e. & Coeff & s.e. \\
\hline 1961 & 0.591 & 0.185 & -0.239 & 0.080 & 0.295 \\
1962 & 0.565 & 0.141 & -0.229 & 0.058 & 0.407 \\
1963 & 0.443 & 0.104 & -0.144 & 0.041 & 0.436 \\
1964 & 0.614 & 0.173 & -0.282 & 0.063 & 0.335 \\
1965 & 0.481 & 0.111 & -0.125 & 0.037 & 0.417 \\
1966 & 0.615 & 0.156 & -0.232 & 0.053 & 0.369 \\
1967 & 0.496 & 0.191 & -0.293 & 0.069 & 0.181 \\
1968 & 0.550 & 0.171 & -0.269 & 0.061 & 0.250 \\
1969 & 0.449 & 0.147 & -0.246 & 0.050 & 0.237 \\
1970 & 0.771 & 0.155 & -0.345 & 0.053 & 0.459 \\
\hline Mean & 0.558 & 0.153 & -0.240 & 0.057 & 0.339 \\
\hline \multicolumn{7}{|c|}{ After Advertising Ban } \\
\hline 1971 & 0.185 & 0.126 & -0.087 & 0.037 & 0.041 \\
1972 & 0.179 & 0.121 & -0.054 & 0.036 & 0.037 \\
1973 & 0.221 & 0.092 & -0.047 & 0.027 & 0.132 \\
1974 & 0.238 & 0.093 & -0.063 & 0.028 & 0.153 \\
1975 & 0.442 & 0.093 & -0.127 & 0.029 & 0.387 \\
1976 & 0.179 & 0.074 & -0.143 & 0.031 & 0.125 \\
1977 & 0.214 & 0.069 & -0.164 & 0.032 & 0.200 \\
1978 & 0.397 & 0.065 & -0.198 & 0.024 & 0.499 \\
1979 & 0.420 & 0.054 & -0.204 & 0.023 & 0.599 \\
\hline Mean & 0.273 & 0.085 & -0.122 & 0.030 & 0.240 \\
\hline
\end{tabular}

I consider two statistics. First, the sum of all entrants' market shares at the year of entry (an entry cohort) for any given year was around $1 \%$, and the sum of all exiting brands' market shares (an exit cohort) for any given year was around $0.1 \%$. Furthermore, Table 3 shows no apparent trend changes in these figures.

Second, I consider the maximum total market share attained by each entry cohort for each year prior 1980 . The maximum cohort market share of entry brands is relatively small for any given year. This feature is even more prominent after the advertising ban. Of all 50 brands that entered after the advertising ban, only two brands, More (introduced in 1975) and Merit (introduced in 1976) ever reached the threshold of 1\% market share. More reached its maximum at $1.18 \%$ and Merit reached $4.32 \%$. For the exiting cohorts, with the exception of one year, no cohort exceeded $1 \%$ of market share at its maximum year. Evidence therefore suggests that the majority of brands that entered or exited during the sample period had relatively little impact on the industry overall.

\section{Estimation}

This section is organized as follows. First, I present the empirical specification of the model. Second, I show the primitives and the estimation procedure. Third, I present the results of the estimation and discuss goodness of fit.

\section{A. Empirical Specification}

For convenience of exposition and ease of estimation, I choose the number of dominant brands to be zero. In section 6 , I conduct an exercise that suggests my results would not change markedly if I added dominant brands.

I specify the goodwill production function $\psi$ in the following way. Given that the goodwill level of brand $j$ at time period $t$ is $s_{j t}$ and that brand $j$ invests $A_{j t}$ in advertising, the total goodwill accumulated in period $t+1$ is $^{20}$ :

$$
s_{j, t+1}=\max \left\{0, \delta s_{j t}+\log \left(\theta_{t} A_{j t}+1\right)+\varepsilon_{j, t+1}\right\}
$$

In numerical computation, I discretize ${ }^{21}$ the state space $s$ into $L+1$ discrete states $\{0,1,2, \ldots, L\}$ for some $L<\infty$.

\footnotetext{
${ }^{20}$ This specification is often used in operational research literature. It is most similar to Dube, Hitsch, and Manchanda (2005), and is discussed in detail in Feichtinger, Hartl, and Sethi (1994), Sethi (1977), Vilcassim, Kadiyali, and Chintagunta (1999).

${ }^{21}$ In computation, I also discretize the private cost shock into $\bar{\nu}$ 's to compute $\sigma(s, \bar{\nu})$. Using discretized $\sigma(s, \bar{\nu})$, I compute the
} 
TABle 3-Industry Entry/Exit Statistics

\begin{tabular}{|c|c|c|c|c|c|c|}
\hline & \multicolumn{3}{|c|}{ Entry } & \multicolumn{3}{|c|}{ Exit } \\
\hline & $\begin{array}{l}\text { Number } \\
\text { in Cohort }\end{array}$ & $\begin{array}{l}\text { Cohort Share } \\
\text { in Entry Year }\end{array}$ & $\begin{array}{r}\text { Maximum } \\
\text { Cohort Share }\end{array}$ & $\begin{array}{l}\text { Number } \\
\text { in Cohort }\end{array}$ & $\begin{array}{l}\text { Cohort Share } \\
\text { in Exit Year }\end{array}$ & $\begin{array}{r}\text { Maximum } \\
\text { Cohort Share }\end{array}$ \\
\hline \multicolumn{7}{|c|}{ Before Advertising Ban } \\
\hline 1961 & 3 & $0.07 \%$ & $0.40 \%$ & 0 & $0.00 \%$ & $0.00 \%$ \\
\hline 1962 & 2 & $0.02 \%$ & $0.02 \%$ & 2 & $0.02 \%$ & $0.07 \%$ \\
\hline 1963 & 6 & $1.27 \%$ & $1.60 \%$ & 2 & $0.02 \%$ & $0.02 \%$ \\
\hline 1964 & 4 & $1.16 \%$ & $2.77 \%$ & 1 & $0.00 \%$ & $0.00 \%$ \\
\hline 1965 & 10 & $0.85 \%$ & $0.87 \%$ & 8 & $0.03 \%$ & $0.05 \%$ \\
\hline 1966 & 5 & $0.86 \%$ & $1.99 \%$ & 7 & $0.04 \%$ & $0.37 \%$ \\
\hline 1967 & 8 & $0.15 \%$ & $0.15 \%$ & 7 & $0.02 \%$ & $0.31 \%$ \\
\hline 1968 & 5 & $0.78 \%$ & $2.58 \%$ & 5 & $0.09 \%$ & $0.27 \%$ \\
\hline 1969 & 6 & $1.28 \%$ & $1.82 \%$ & 7 & $0.07 \%$ & $1.36 \%$ \\
\hline 1970 & 8 & $0.31 \%$ & $3.93 \%$ & 5 & $0.10 \%$ & $0.15 \%$ \\
\hline \multicolumn{7}{|c|}{ After Advertising Ban } \\
\hline 1971 & 6 & $0.10 \%$ & $0.10 \%$ & 7 & $0.07 \%$ & $0.17 \%$ \\
\hline 1972 & 1 & $0.03 \%$ & $0.06 \%$ & 4 & $0.08 \%$ & $0.18 \%$ \\
\hline 1973 & 3 & $0.15 \%$ & $0.15 \%$ & 1 & $0.01 \%$ & $0.04 \%$ \\
\hline 1974 & 7 & $0.17 \%$ & $0.17 \%$ & 3 & $0.07 \%$ & $0.07 \%$ \\
\hline 1975 & 12 & $1.25 \%$ & $2.34 \%$ & 8 & $0.08 \%$ & $0.17 \%$ \\
\hline 1976 & 8 & $0.96 \%$ & $6.46 \%$ & 11 & $0.06 \%$ & $0.09 \%$ \\
\hline 1977 & 3 & $0.42 \%$ & $0.44 \%$ & 0 & $0.00 \%$ & $0.00 \%$ \\
\hline 1978 & 2 & $0.01 \%$ & $0.01 \%$ & 0 & $0.00 \%$ & $0.00 \%$ \\
\hline 1979 & 5 & $1.39 \%$ & $1.87 \%$ & 3 & $0.03 \%$ & $0.20 \%$ \\
\hline 1980 & 3 & $0.26 \%$ & $0.26 \%$ & 5 & $0.02 \%$ & $0.45 \%$ \\
\hline
\end{tabular}

Since I know the probability of realizing a particular $\varepsilon$ from its distribution $\Phi$, I can construct the probability transition function $\tilde{\rho}_{t}\left(s^{\prime} \mid s, A\right)$ (see Appendix for the detailed specification of $\tilde{\rho}_{t}$ and a proof that under this specification a unique optimal solution for $A$ always exists).

The market share function is specified as follows:

$$
D\left(s_{j t}, s_{t}\right)=\frac{s_{j t}+1}{\sum_{i=1}^{J_{t}}\left(s_{i t}+1\right)}
$$

This specification is a special case of the logit demand from the discrete-choice models often used in the empirical industrial organization literature (e.g., Berry, Levinsohn, and Pakes (1995)). In this specification, there is no outside option. Because of this assumption, advertising in this model does not change aggregate industry demand.

The profit function is:

$$
\pi_{t}\left(s_{j}, s\right)=(1-\xi) P_{t} M_{t} D\left(s_{j}, s\right)
$$

Here, $P_{t}$ is the real unit price of cigarettes. Since the cigarette industry exhibits little price competition, I abstract away from pricing decisions, and set $P_{t}$ as the industry price. Every brand takes $P_{t}$ as given in each period. The term $\xi$ is the operating cost margin, and I assume it is constant over time ${ }^{22}$. The overall market size is $M$, and there is no fixed cost of cigarette production. In addition, the advertising expenditure function is $C(A, \nu)=\max \{0,(1+\nu) A\}$.

\section{B. Estimation Procedure}

I choose the annual discount factor to be $\beta=0.95$. I choose the maximum obtainable goodwill stock level $L$ so that the probability of reaching $L$ in any period is less than $0.01 \%$. $L$ is 20 in this estimation. I use market size $M_{t}$ and industry price $P_{t}$ directly from data. I computes $\lambda$ to be the average number of entry brands, so $\lambda=5$. Moreover, the number of active brands for any given period is the average number of active brands $\chi=42$. The

expected value function $V(s, \bar{\nu})$. In numerical simulation of the model, I draw $\nu$ randomly from $\Gamma$, and use the value function $V(s, \bar{\nu})$, where $\bar{\nu}$ is the closest to $\nu$. This allows me to compute $\sigma(s, \nu)$ as a continuous function of $\nu$.

${ }^{22}$ Ideally, one should estimate the cost margin directly from the data. I do not have data on cigarette product costs at the present time. I assume for now that $\xi=0$. 
entry rate is $\phi=\lambda / \chi=12 \%$.

The initial industry state $s_{0}$ is directly estimated from the data by fitting the market share distribution in 1960 . This is important for fitting the market shares in later periods.

The list of parameters to be estimated include advertising efficiency parameters $\left\{\theta_{t}\right\}$, depreciation parameter $\delta$, forecast error variance $\sigma_{\varepsilon}^{2}$ and cost shock variance $\sigma_{\nu}^{2}$.

I assume that $\theta$ is the same for all pre-ban years 1960-1970, and that prior to the ban, brands do not know it is coming. To incorporate industry learning, I assume $\theta$ evolves in three stages. $\theta_{t}$ is constant for the years 1971-1974. Learning in $\theta$ occurs between 1974 and 1977. For these years, $\theta$ increases in a linear fashion with slope $S L O P E_{\theta}$. Finally, for the years 1977-1980, $\theta_{t}$ is assumed once again to be constant. I also set $\theta_{t}=\theta_{1977-1980}$ for years after 1980. After the ban, brands have perfect foresight on the learning of $\left\{\theta_{t}\right\}$. Use $\Theta^{0}$ to denote the vector of all parameters. There are a total of 6 parameters to be estimated ${ }^{23}$.

Using the Oblivious Equilibrium model, I simulate the model for 100 periods following 1980, holding $M_{t}$ and $P_{t}$ fixed at the 1980 levels.

I use a simple moment matching algorithm to estimate model parameters ${ }^{24}$. From the data, I have sales $S A L E_{j, t}=M_{t} \cdot D_{j t}$ and total advertising expenditures $A D V_{j, t}=\left(1+\nu_{j t}\right) A_{j t}$. I choose the following moments from data to match the simulated data moments.

- Total industry advertising spending each period $\sum_{j} A D V_{j, t}$.

- Descriptive parameters from the descriptive regression discussed in the Data section:

$$
\left[\log \left(S A L E_{j, t+1}\right)-\log \left(S A L E_{j, t}\right)\right]=C O N_{t}+\kappa_{t}\left(\log \left(A D V_{j, t} / S A L E_{j, t}+1\right)\right)+E R R O R_{j, t+1}
$$

There are a total of 60 moments. Notice that the simple descriptive regression is an approximation of first order condition. Denote the data moments $\Upsilon^{0}$.

Now for a given parameter value $\Theta$, I can consider $N$ simulated paths of $\left\{\widehat{S A L E}_{j t}^{n}\right\}$ and $\left\{\widehat{A D V}_{j t}^{n}\right\}, n=1, \ldots, N$; based on independent drawings of error terms denoted by $\left\{\widehat{\varepsilon}_{j t}^{n}\right\}$ and $\left\{\widehat{\nu}_{j t}^{n}\right\}$. For each of these simulated paths, I can similarly construct simulated moments $\widehat{\Upsilon}^{n}(\Theta)$. The idea then is simply to obtain a value of $\Theta$ in order to have

$$
\frac{1}{N} \sum_{n=1}^{N} \widehat{\Upsilon}^{n}(\Theta)
$$

close to $\Upsilon^{0}$. Then, the estimator $\Theta^{*}$ is defined as a solution of a minimum distance problem:

$$
\Theta^{*}=\arg \min _{\Theta}\left(\Upsilon^{0}-\frac{1}{N} \sum_{n=1}^{N} \widehat{\Upsilon}^{n}(\Theta)\right)^{\prime} \Omega\left(\Upsilon^{0}-\frac{1}{N} \sum_{n=1}^{N} \widehat{\Upsilon}^{n}(\Theta)\right)
$$

$\Omega$ is the optimal weighting matrix ${ }^{25}$.

\section{Estimation Results and Goodness of Fit}

The parameter estimates and their standard errors are presented in Table 4.

In addition, Figure 4 shows the estimated advertising efficiency levels over time with the pre-ban advertising efficiency level normalized to 100.Advertising efficiency experienced a 50\% decrease at the onset of the advertising ban. It subsequently recovered to just below $80 \%$ of the 1970 level. The fact that advertising efficiency did not recover to pre-ban levels is significant, since total advertising spending well exceeded the pre-ban level. Therefore one cannot fully attribute the increase in advertising spending after the ban to an improvement in advertising technology.

As shown in Table 4, the depreciation rate is small. At a rate of $\delta=0.958$, with no advertising, one unit of goodwill stock will decay to half a unit in approximately 16 years time ${ }^{26}$. In other words, there is significant

\footnotetext{
${ }^{23}$ This piece-wise linear assumption on $\theta_{t}$ is strong since I impose the periods of learning. Alternatively, I can allow the periods of learning to be estimated. This adds computational burden. However, the results do not change much.

${ }^{24}$ This moment matching technique is closely related to an indirect inference estimator, see Genton and Ronchetti (2003), Gourieroux, Monfort, and Renault (1993).

${ }^{25}$ I use the bootstrap method to obtain the standard errors of estimates.

${ }^{26}$ This depreciation rate is higher than the estimate provided in Roberts and Samuelson (1988), which is 0.892 with standard error 0.024 .
} 
TABle 4-Estimation Results

\begin{tabular}{|c|cc|}
\hline & Coeff & s.e \\
\hline$\theta_{1960-1970}$ & 0.068 & 0.0008 \\
$\theta_{1971-1974}$ & 0.034 & 0.0036 \\
SLOPE & 0.007 & 0.0004 \\
$\delta$ & 0.958 & 0.0087 \\
$\sigma_{\varepsilon}$ & 1.545 & 0.0035 \\
$\sigma_{\nu}$ & 0.102 & 0.0001 \\
\hline
\end{tabular}

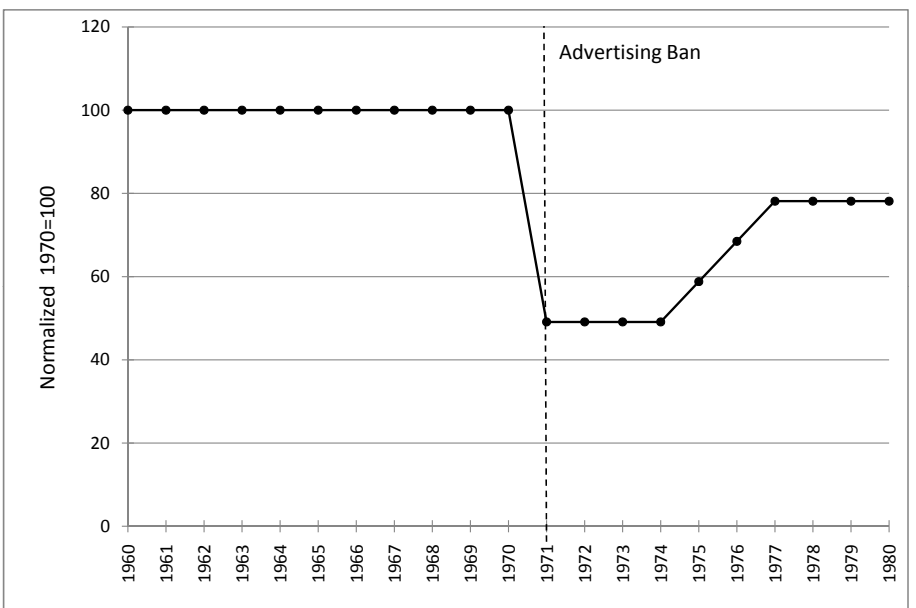

Figure 4. Estimated Advertising Efficiency

carryover effect of brand goodwill stock. In addition, notice that random noise is significant. The standard deviation of $\varepsilon$ is 1.5 units of goodwill stock. This is significant because to increase the goodwill stock by the same amount, a brand would have needed to spend $\$ 53$ million on advertising prior to the ban.

Figure 5 shows the goodness of fit to the total industry spending. The solid line represents the data, and the dotted line represents model prediction. The model fits the total industry spending levels in billions of (year 2000) dollars.

\section{Counterfactual Experiments}

In this section, I contrast the estimated model with the following two experiments ${ }^{27}$. The first experiment is to determine the evolution of the industry if there were no ban. I model this by assuming that advertising efficiency stays constant $\left(\theta_{t}=\theta_{1960-1970}\right.$ for all $\left.t=\{1971, \ldots, 1980\}\right)$. The second experiment allows the ban, such that efficiency drops after 1971. However, I do not allow advertising efficiency to recover in this experiment, so industry learning is shut down $\left(\theta_{t}=\theta_{1971-1974}\right.$ for all $\left.t=\{1971, \ldots, 1980\}\right)$.

Experiment (1) provides the baseline case to investigate the effects of the advertising ban. Specifically, it reveals the impact of the ban on the overall increase in industry advertising spending, on brand heterogeneity and market structure, and on brand profitability. By comparing the estimated model to experiment (2), I show that industry learning is not the major factor driving the overall increase in advertising spending after the ban.

\section{A. Aggregate Advertising Spending}

Figure 6 shows total industry advertising spending from the two above-mentioned experiments.

As in Figure 5, the solid line in each sub-figure represents the data, while the dotted line represents model prediction. In the first experiment, when there is no ban, the model predicts no significant shift in the trend of total advertising spending. This shows that the advertising ban and subsequent industry learning have contributed to the overall increase in advertising spending. In the second experiment, the industry cannot learn to improve its advertising efficiency level after the ban. The model predicts that advertising would experience an initial drop, but then recover quickly. By the mid-1970s, total advertising spending in this case would exceed that in the no ban

${ }^{27}$ I do not re-estimate the model, but rather use the estimated parameter in these experiments. 


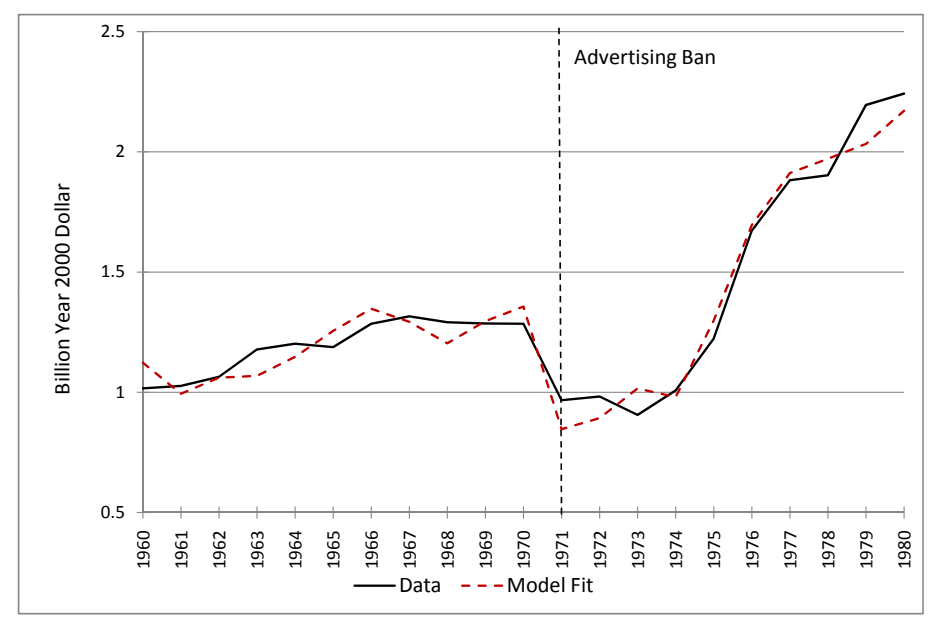

Figure 5. Model Fit of Total Industry Spending

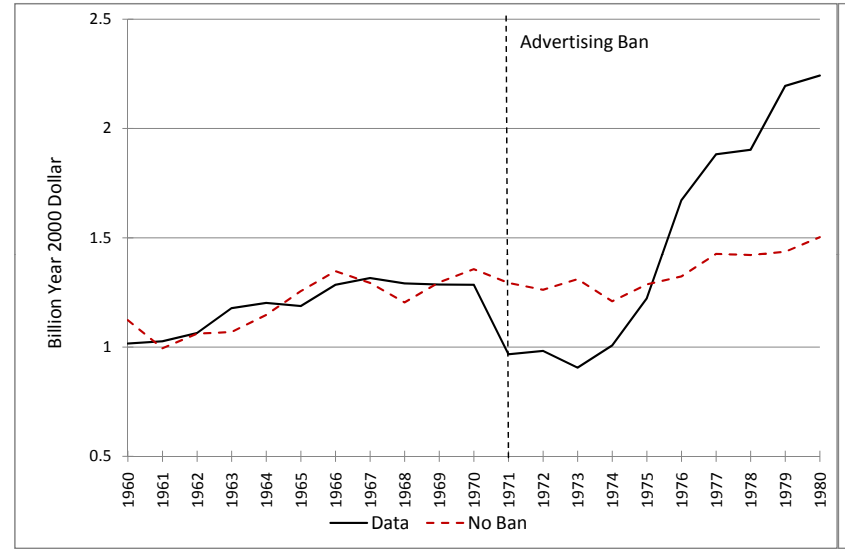

(a) Scenario 1: No Ban

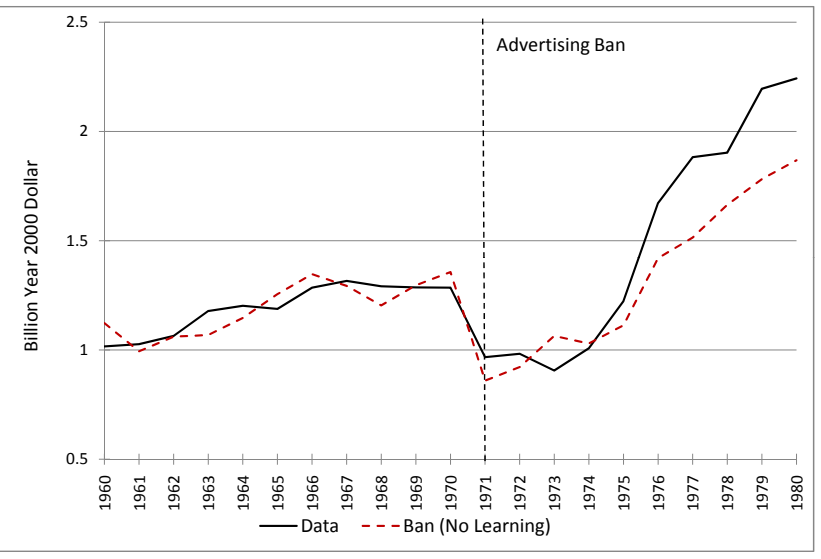

(b) Scenario 2: No Learning

Figure 6. Experiments: Total Industry Advertising Spending

case. Even without learning, the model can explain $70 \%$ of the increase in total advertising spending after 1974 . This shows that industry learning is not the major factor driving the overall increase in advertising spending after the ban.

\section{B. Brand-level Impact of the Advertising Ban}

The above analysis looks at the aggregate impact on spending. In this subsection, I consider the effects of policy at the brand level.

Figure 7 shows how the model fits to the market share distribution for the selected years of 1961, 1971 and 1980.

Sub-figures (a), (b), and (c) show histograms the depict the percentage of brands in each market share bin. Each bin is $0.8 \%$ in width. The figures also show the average market share distributions predicted by the model. Although market shares are not moments of the estimation (except for the initial condition), the model fits the general pattern of the market share distribution. In sub-figure (d), I overlay the market share distribution predictions for the three years. Sub-figure (d) shows that market share distribution does not change immediately after the ban. However, the combination of goodwill stock depreciation and low advertising efficiency eventually skewed the distribution towards a higher fraction of small brands. Brand heterogeneity is an important model element for capturing this feature of the data.

Figure 8 shows the model fit to advertising spending by brand size for the years 1961, 1971 and 1980. Clearly, advertising is an increasing and concave function of brand size. Similar to Figure 7, sub-figures (a), (b) and (c) show that the model generally fits the advertising spending data. Sub-figure (d) shows that, immediately after the 


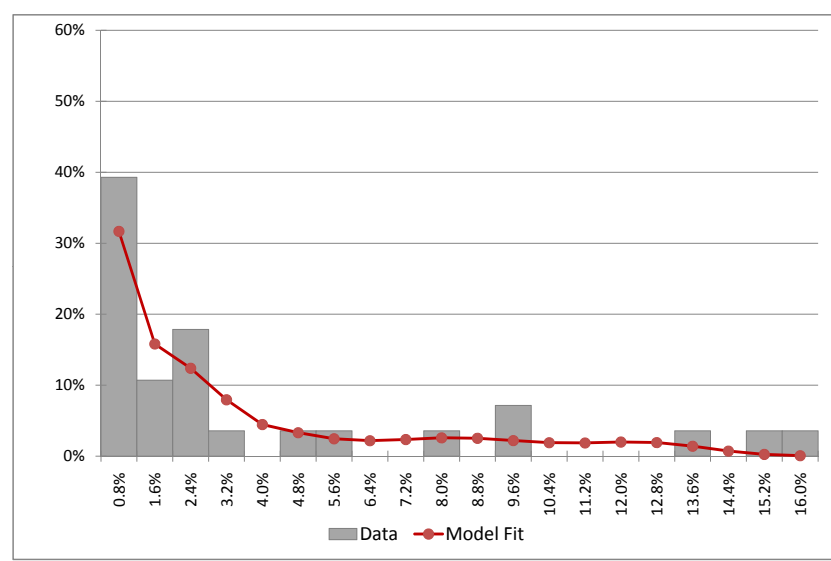

(a) 1961

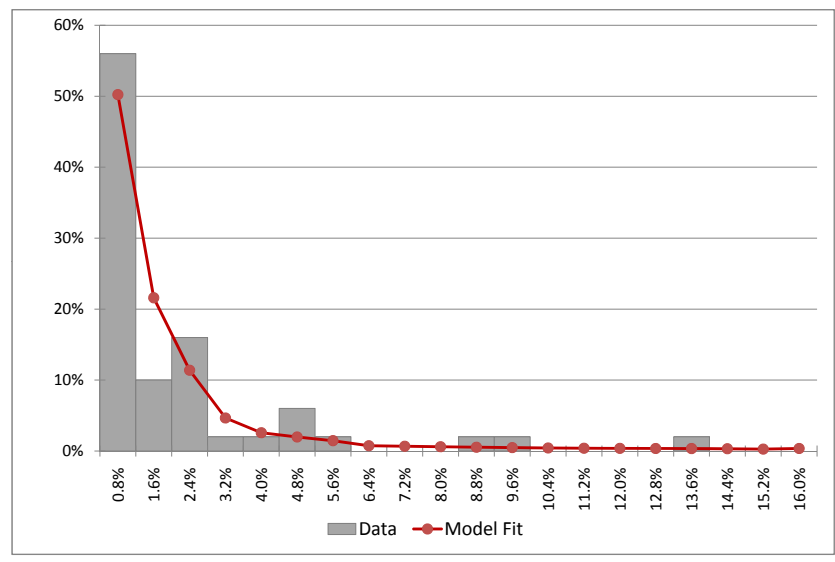

(c) 1980

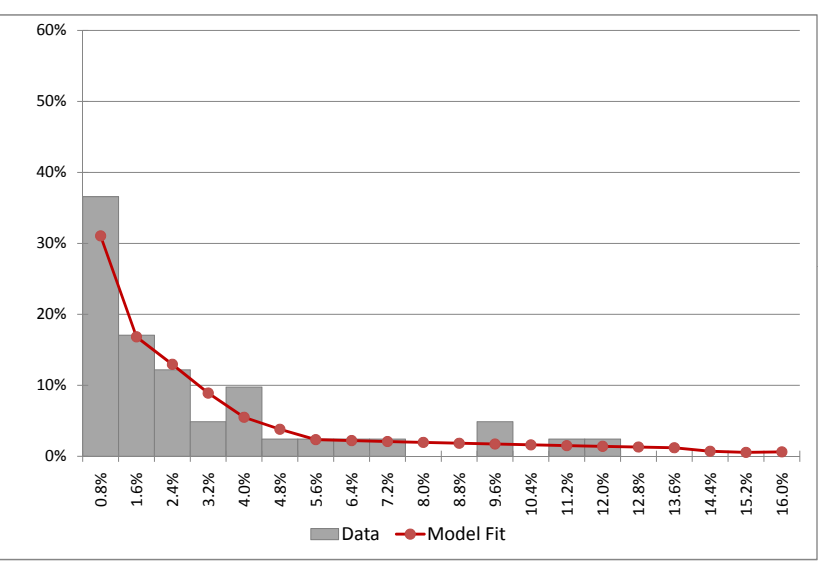

(b) 1971

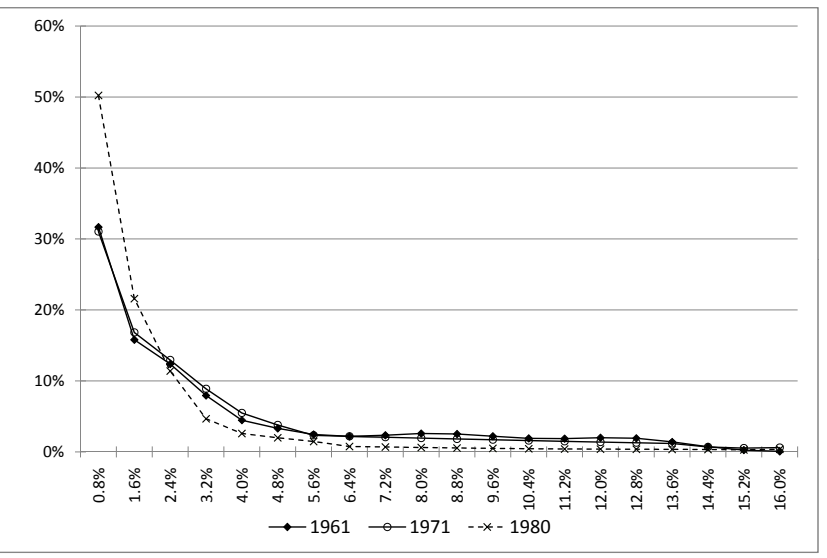

(d) Model Comparison For Selected Years

Figure 7. Goodness of Fit: Market Share Distribution for Selected Years

ban, brands of almost all different sizes experience a decrease in advertising spending. Smaller brands, however, are disproportionately affected. Eventually, in 1980, all brand sizes except for the very smallest ones advertise more.

Next, I show how market share distribution and advertising spending change under the counterfactual experiments. Since the previous subsection shows that industry learning is not the major factor driving the overall increase in advertising spending after the ban, I only compare the case with no ban to the case with a ban but no efficiency recovery

Figure 9 compares the 1980 distribution of brand market shares in the two cases.

The ban reduces the efficiency parameter $\theta$. The left panel of figure 9 shows that the smaller $\theta$ is, the more skewed to the left the market share distribution is. In other words, the less efficient advertising becomes, the higher the proportion of small brands. In the right panel of Figure 9, sub-figure (b) presents another way of looking at the market share distribution. Sub-figure (b) shows the number of brands of each brand size compared to the model (with the model quantities normalized to one). Compared to no ban, the advertising ban reduces the number of brands for all brands with $1.6 \%$ or more market share. For brands with $10.4 \%$ or more market share, the advertising ban reduces the number of brands by $2 / 3$ or more. Figure 10 shows the expected total market share by brand size in 1980 .

Considering the brands with $2.4 \%$ or more market share, the advertising ban actually reduces the expected market share, because the probability of becoming a big brand decreases significantly after the ban.

Figure 11 shows the comparison of advertising by brand size in 1980 under the two cases.

We can see that the model with an advertising ban predicts a higher advertising level compared to the no ban case mainly because brands with $2.4 \%$ or more market share advertise more.

Finally, I compare brand-level advertising, market share, and profits in 1980 under the estimated model and the baseline case without an advertising ban. In 1980, $23.9 \%$ of all brands would advertise more as compared to the case with no ban, while $7.7 \%$ would advertise less (the rest of the brands were either new entrant brands or brands that had already exited). A total of $19.4 \%$ of brands have higher market share, while $12.3 \%$ have lower. Meanwhile, $9 \%$ of brands have greater profits than that in the case with no ban, while $22.6 \%$ have less. In other words, a 


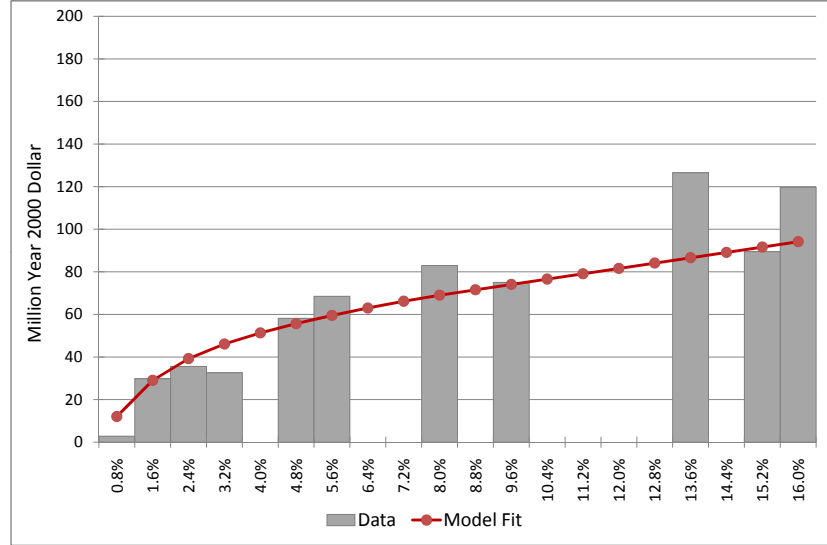

(a) 1961

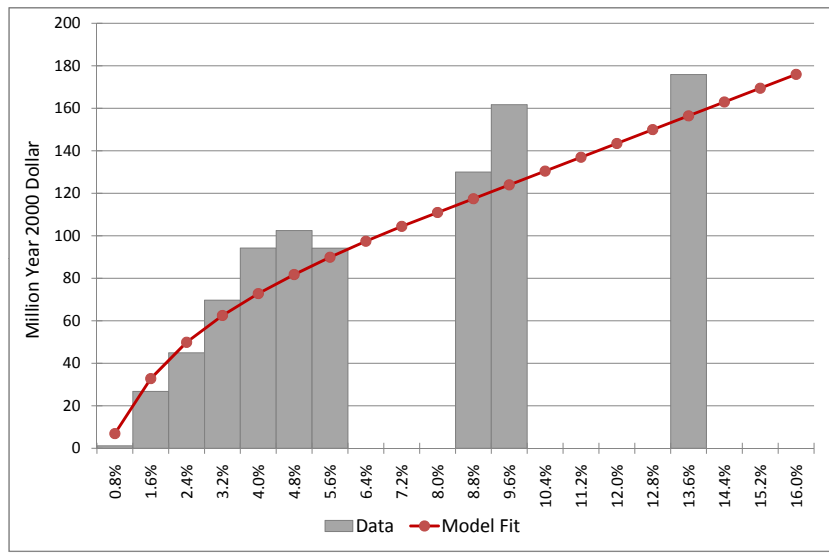

(c) 1980

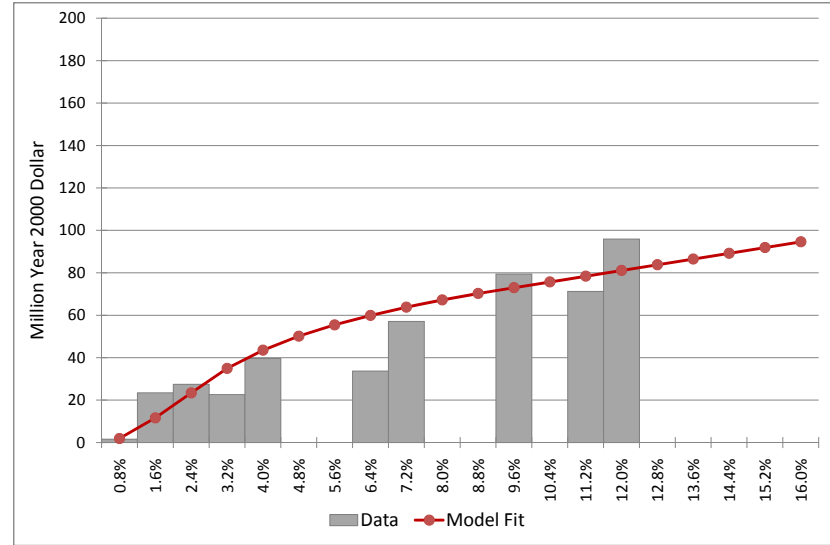

(b) 1971

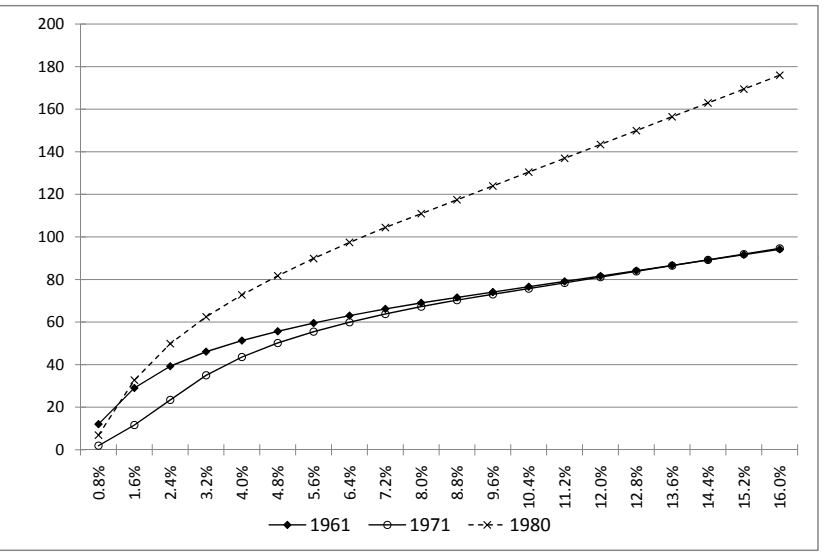

(d) Model Comparison For Selected Years

Figure 8. Goodness of Fit: Advertising Spending by Brand Size for Selected Years

relatively small fraction of brands would benefit from the advertising ban, while a considerably large fraction would be hurt by it. Out of the brands that benefited from the advertising ban, the average market share was $1.79 \%$, while those who were hurt had an average market share of $0.46 \%$. This indicates that larger brands benefited from the advertising ban.

\section{Dominant Brands}

In this section, I use the estimated parameters from the no-dominant-brand environment to simulate the model under the one-dominant-brand and two-dominant-brand environments ${ }^{28}$. The purpose of this section is two-fold. First, as shown in the data section, a few top brands have a very large portion of total sales throughout the history of the cigarette industry. This section shows that the existence of dominant brands does not significantly affect advertising spending or brand-level market share distribution. Second, I compare the results under these three environments, and show that NPOE is a good approximation of Markov Perfect Equilibrium.

I use Winston's sales as the dominant brand size in the simulation for the one-dominant-brand environment, and I use Winston and Marlboro's sales as the dominant brand sizes in the simulation for the two-dominant-brand environment. Using the same sets of random errors, I can generate model predictions and compare them to those generated under the no-dominant-brand environment.

Figure 12 shows simulated aggregate advertising spending using the same estimated parameters and the same series of error draws under the three different environments.

Figure 13 shows brand-level advertising spending under different dominant brand schemes. In these two figures,

\footnotetext{
${ }^{28}$ Computations under these environments are time costly. To compute the equilibrium once, it requires about 5 hours for the one-dominant-brand environment, and about 40 hours for the two-dominant-brand environment.
} 


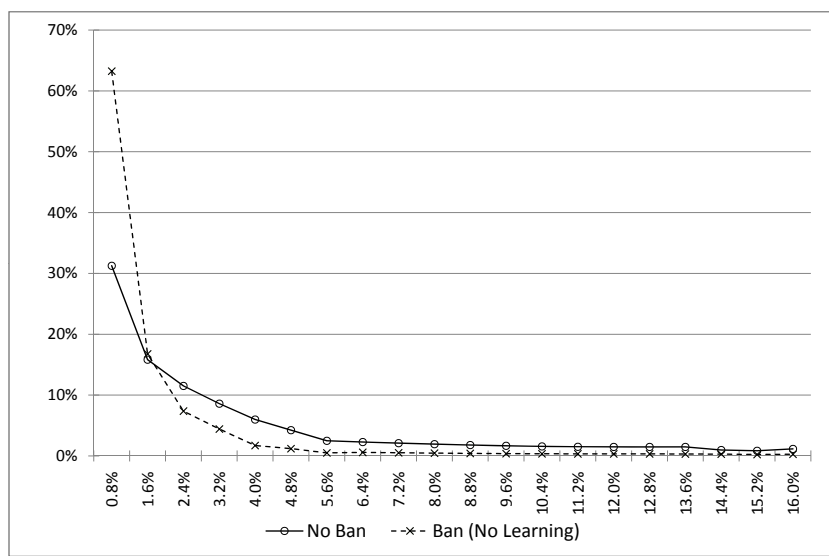

(a) Market Share Distribution

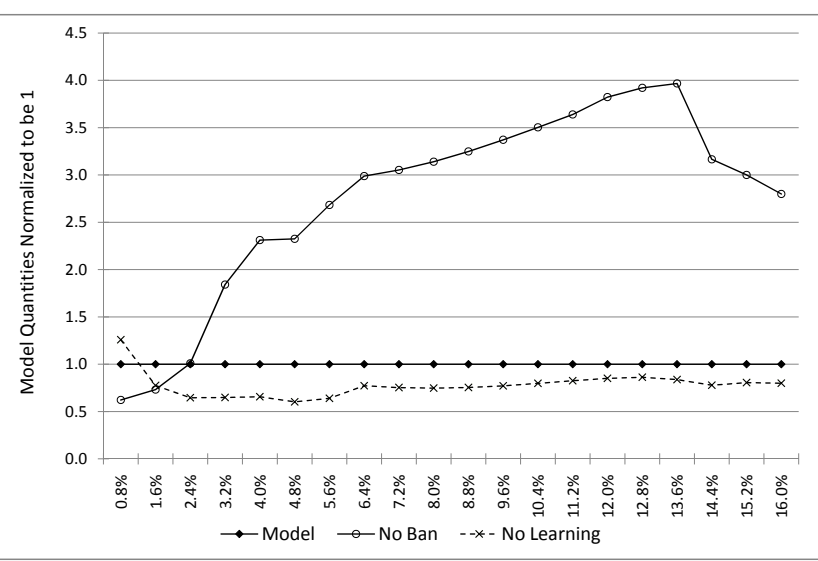

(b) Number of Brands by Brand Size

Figure 9. Comparison of 1980 Brand-Level Market Shares

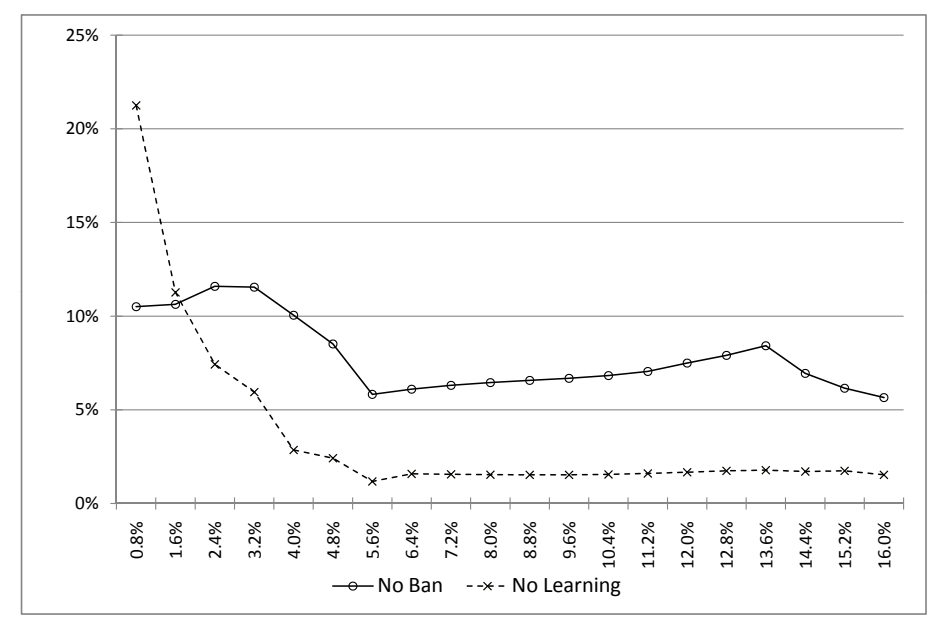

Figure 10. Comparison of 1980 Expected Total Market Shares by Brand Size

the model predictions from the three different model environments are fairly close. With no dominant brands, the model slightly under predicts advertising spending, since the strategic element of advertising is ignored.

Figure 14 shows the market share distributions prediction under different dominant brand schemes for the selected years 1961, 1971, and 1980. Similarly, the model predictions under the three different model environments are fairly close. The model with no dominant brands tends to under-predict the proportion of small brands.

The difference in results between the one-dominant-brand environment and the two-dominant-brand environment are negligible. This suggests that the results will not change much by adding additional dominant brands. Therefore, NPOE does fairly well in approximating the Markov Perfect Equilibrium in which all brands are dominant brands.

\section{Conclusion}

After a TV/Radio advertising ban in 1971, total cigarette industry advertising spending fell, but then recovered and exceeded pre-ban levels. This occurred while price and industry demand remained largely unchanged. The dynamic advertising model developed in this paper explains this puzzling feature of the industry. The model successfully incorporates industry dynamics and the wide heterogeneity existing across firms in this industry, showing that brand-level heterogeneity and industry dynamics are important elements for modeling advertising regulation changes in an industry.

In addition, through the estimation and model results, this paper finds that advertising efficiency dropped significantly due to the partial advertising ban. This efficiency improved after the ban, but never recovered to pre-ban levels. Due to this change in advertising efficiency, market share was skewed more toward small brands following the ban. Large brands were likely to advertise more, which contributed to the overall advertising increases. In terms of profits, the partial advertising ban benefited a few large brands while hurting a large fraction of smaller brands. 


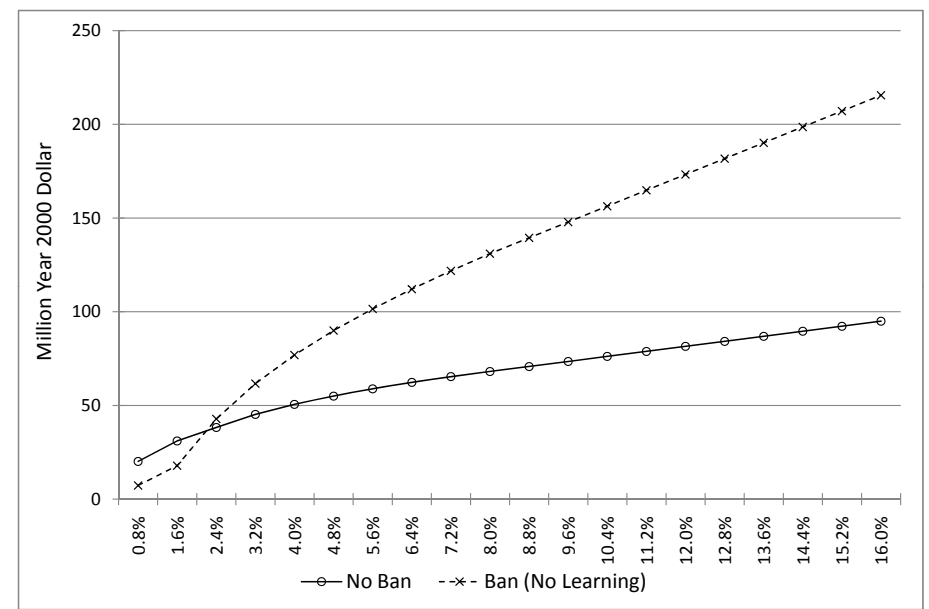

Figure 11. Comparison of 1980 Advertising by Size of Brands

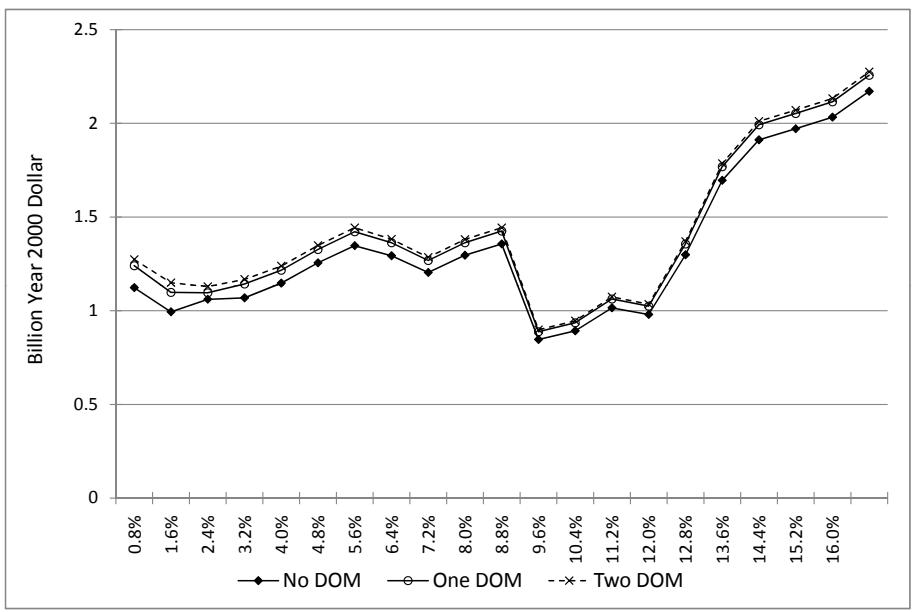

Figure 12. Aggregate Advertising Spending Under Different Dominant Brand Environments

In future research, I plan to incorporate strategic entry and exit, and consider coordination in advertising decisions among brands of the same company.

\section{REFERENCES}

Alonso, R., W. Dessein, and N. Matouschek. "When Does Coordination Require Centralization." American Economic Review forthcoming.

Bagwell, K. "The Economic Analysis of Advertising." Working Paper .

Bajari, P., C.L. Benkard, and J. Levin. "Estimating Dynamic Models of Imperfect Competition." Econometrica 75, 5: (2007) 1331-1370.

Benkard, C.L. "A Dynamic Analysis of the Market for Wide-Bodied Commercial Aircraft." The Review of Economic Studies 71, 3: (2004) 581-611.

Berry, S., J. Levinsohn, and A. Pakes. "Automobile Prices in Market Equilbrium." Econometrica 63, 4: (1995) 841-890.

Carter, S. M. "Tobacco Document Research Reporting." Tobacco Control 14: (2007) 368-376.

Doraszelski, U., and S. Markovich. "Foundation of Markov-perfect Industry Dynamics: Existence, Purification and Multiplicity." Working Paper . 


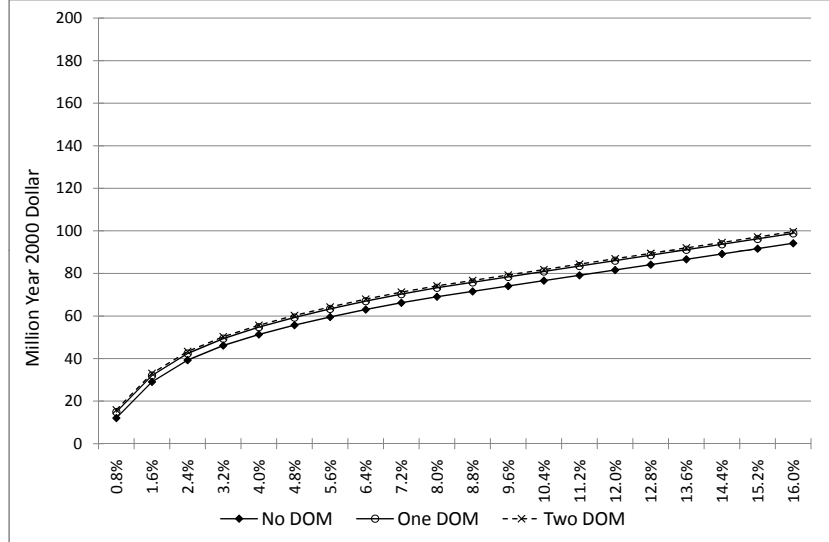

(a) 1961

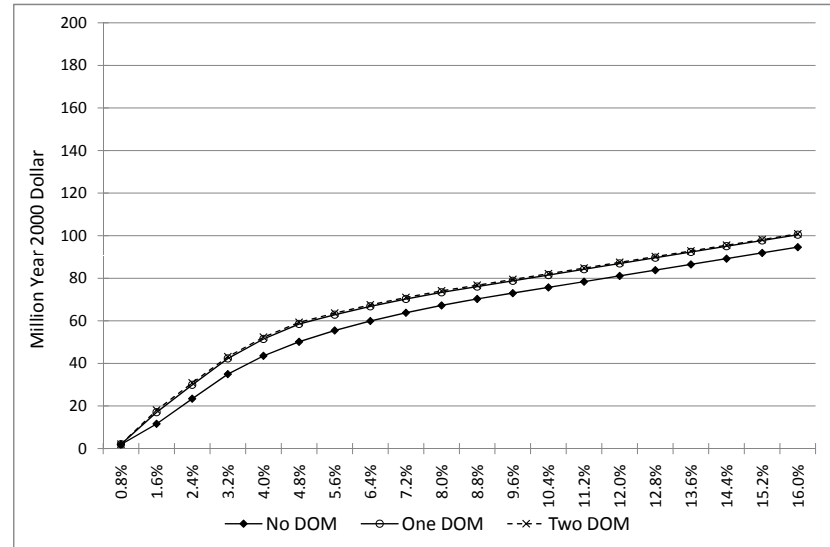

(b) 1971

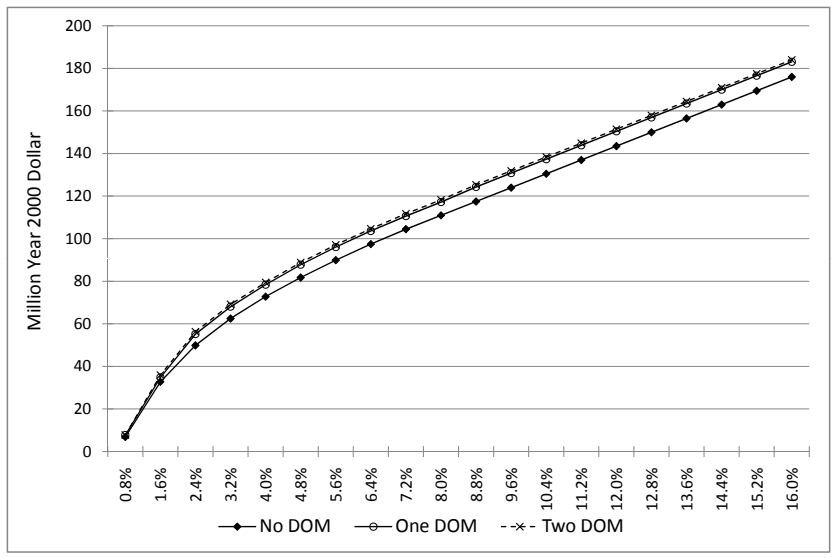

(c) 1980

Figure 13. Brand-Level Advertising Spending Under Different Dominant Brand Environments

Doraszelski, U., and M. Satterthwaite. "Foundation of Markov-perfect Industry Dynamics: Existence, Purification and Multiplicity." Working Paper .

Dube, J., G. Hitsch, and P. Manchanda. "An Empirical Model of Advertising Dynamics." Quantitative marketing and economics 3, 2: (2005) 107-144.

Duffy, Martyn. "Econometric Studies of Advertising, Advertising Restrictions and Cigarette Demand: A Survey." International Journal of Advertising 15: (1996) 1-23.

Eckard, W. "Competition and the cigarette TV advertising ban." Economic Inquiry 29, 1: (1991) 119-133.

Ericson, Richard, and Ariel Pakes. "Markov-Perfect Industry Dynamics: A Framework for Empirical Work." The Review of Economic Studies 62, 1: (1995) 53-82.

Farr, S., C. Tremblay, and V. Tremblay. "The welfare effect of advertising restrictions in the U.S. cigarette industry." Review of Industrial Organization 18: (2001) 147-160.

Feichtinger, Gustav, Richard F. Hartl, and Suresh P. Sethi. "Dynamic Optimal Control Models in Advertising: Recent Developments." Management Science 40, 2: (1994) 195-226.

Friedman, James W. "Advertising and Oligopolistic equilibrium." The Bell Journal of Economics 14, 2: (1983) $464-473$.

Genton, M., and E. Ronchetti. "Robust Indirect Inference." Journal of the American Statistical Association 98, 461: (2003) 67-76. 


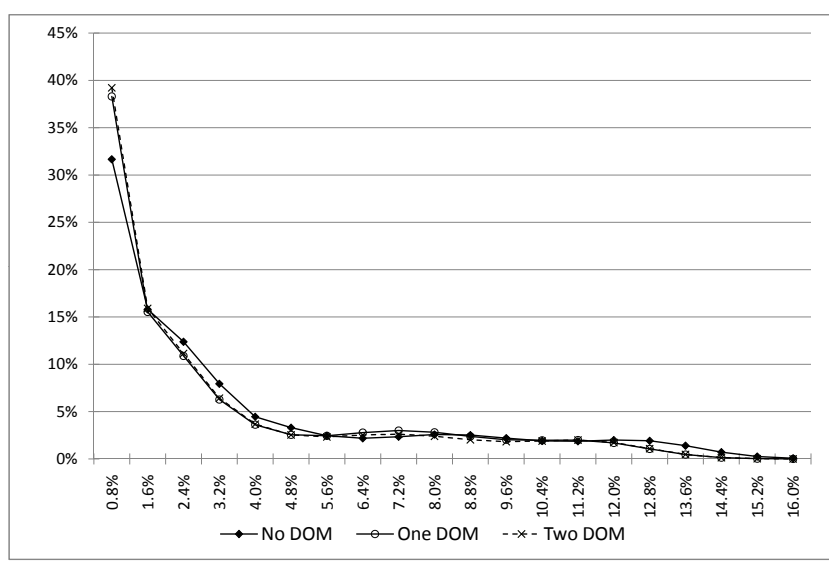

(a) 1961

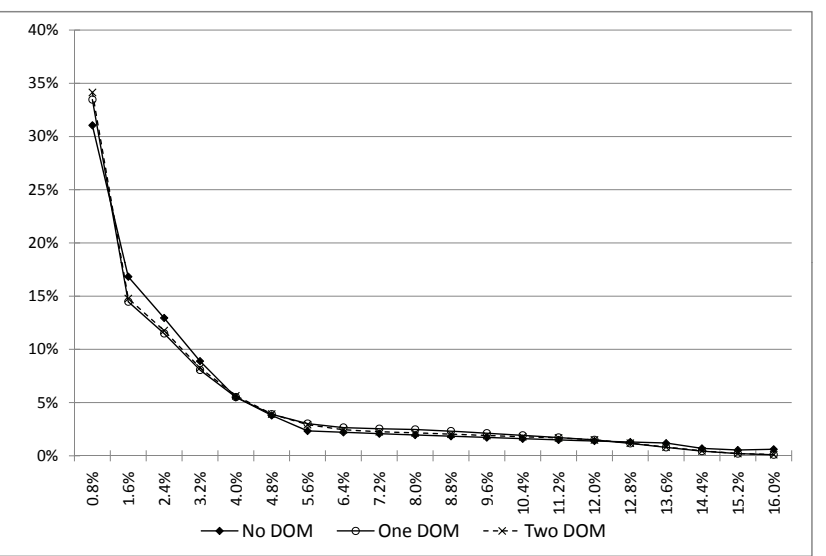

(b) 1971

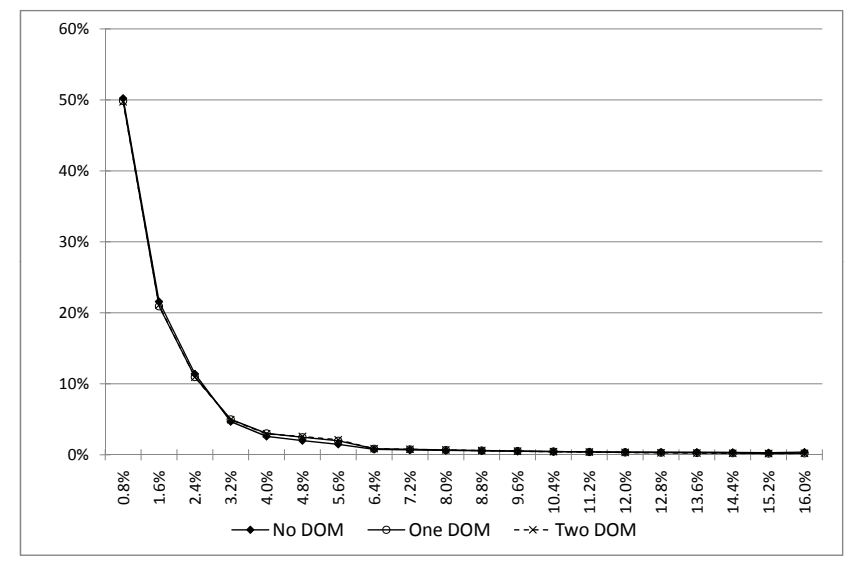

(c) 1980

Figure 14. Market Share Distribution Under Different Dominant Brand Environments

Gourieroux, C., A. Monfort, and E. Renault. "Indirect Inference." Journal of applied econometrics 8, 1: (1993) S85-S118.

Hamilton, James L. "The Demand for Cigarettes: Advertising, the Health Scare, and the Cigarette Advertising Ban." The Review of Economics and Statistics 54, 4: (1972) 401-411.

Martin, Andrew. "Trying Again for a Bill to Limit Tobacco Ads." New York Times http://www. nytimes.com/2007/02/16/business/16tobacco.html.

Mitchell, Mark L., and J. Harold Mulherin. "Finessing the political system: the cigarette advertising ban." Southern Economic Journal 54, 4: (1988) 855-862.

Roberts, J., and L. Samuelson. "An Empirical Model of Dynamic, Nonprice Competition in an Oligopolistic Industry." Rand Journal of Economics 19, 2: (1988) 200-220.

Sethi, Suresh P. "Dynamic Optimal Control Models in Advertising: A Survey." SIAM Review 19, 4: (1977) $685-725$.

Tan, Wei. "A Dynamic Analysis of the U.S. Cigarette Market and Anti-smoking Policies." Working Paper .

Telser, Lester. "Advertising and Cigarettes." The Journal of Political Economy 70, 5: (1962) 471-499.

Vilcassim, Naufel J., Vrinda Kadiyali, and Pradeep K. Chintagunta. "Investigating Dynamic Multifirm Market Interactions in Price and Advertising." Management Science 45, 4: (1999) 499-518.

Weintraub, G., C.L. Benkard, and B. van Roy. "Computational Methods for Oblivious Equilibrium." Working Paper . 
. "Extensions to Oblivious Equilibrium." Working Paper .

"Markov Perfect Industry Dynamics with Many Firms." Working Paper .

\section{Appendix: Not for Publication}

\section{Mathematical Appendix}

\section{Expected Fringe Brand State}

For convenience, denote $\tilde{z}_{t}(s, w)$ to be the $s$ component of $\left.\tilde{z}_{\left(\sigma, y_{0}, z_{0}\right), t}(w)\right)$. Here I assume $w=y$ for simplicity.

Under strategy profile $\sigma$, I denote the probability of the dominant states being $y$ in time period $t$ to be $\Pi_{t}(y \mid \sigma)$, and denote the probability of dominant brands transition from state $y^{\prime}$ in period $t-1$ to $y$ in period $t$ given they use strategy $\sigma$ to be $\rho_{t}^{d o m}\left(y \mid y^{\prime}, \sigma\right)$, where $\rho_{t}^{d o m}\left(y \mid y^{\prime}, \sigma\right)$ is the product of all dominant brands' transition probabilities. Then, the following relationships hold:

$$
\Pi_{t+1}(y \mid \sigma)=\int_{y^{\prime}} \Pi_{t}\left(y^{\prime} \mid \sigma\right) d \rho_{t}^{d o m}\left(y \mid y^{\prime}, \sigma\right)
$$

where $\Pi_{0}\left(y_{0}\right)=1$, and $\Pi_{0}(y)=0$ for all $y \neq y_{0}$. Given the definition the $\Pi$, I define $\zeta_{t}(s, y)=\tilde{z}_{t}(s, y) \Pi_{t}(y)$, then:

$$
\zeta_{t+1}(s, y)=\int_{s^{\prime}} \int_{y^{\prime}} \zeta_{t}\left(s^{\prime}, y^{\prime}\right) d \rho_{t}^{d o m}\left(y \mid y^{\prime}, \sigma\right) d \tilde{\rho}_{t}\left(s \mid s^{\prime}, \sigma\right)+\lambda \rho^{e}(s) \Pi_{t}(y)
$$

where $\rho^{e}(s)$ is probability of entrant brand obtaining state $s$ in its initial period. Given equation (7) and equation (8), I can obtain $\tilde{z}_{\left(\sigma, y_{0}, z_{0}\right), t}(y)$ and $\Pi_{t}(y \mid \sigma)$ iteratively.

\section{Transition Probability}

Here I show the transition function for a more general case than the one shown in the main part of the paper. Slightly modify equation (5) and use the following notation:

$$
\begin{aligned}
& s_{j, t+1}^{*}=\delta s_{j t}+f\left(A_{j t}\right) \\
& \tilde{s}_{j, t+1}=s_{j, t+1}^{*}+\varepsilon_{j, t+1}
\end{aligned}
$$

$\tilde{s}$ is continuous, and $\tilde{s}_{j, t+1}$ is discretized into $s_{j, t+1}$. And consider the discretized state space $\bar{g} \in\left\{\bar{g}_{0}, \ldots, \bar{g}_{L}\right\}$, where $\bar{g}_{k}-\bar{g}_{k-1}=d$ for all $k$ (For the paper, $\bar{g}_{0}=0$ and $d=1$ ).

Similar to Benkard (2004), I use a binomial random variable to specify the period $t+1$ goodwill level $s_{j, t+1}$. For any given $\varepsilon$, the probability of $s_{j, t+1}=\bar{g}_{k}$ is:

$$
\operatorname{Pr}\left(\bar{g}_{k} \mid \tilde{s}, \varepsilon\right)=\left\{\begin{array}{cl}
\frac{\tilde{s}_{-}-\bar{g}_{k-1}}{\bar{g}_{k}-\bar{g}_{k-1}} & \text { if } \bar{g}_{k-1} \leq \tilde{s}<\bar{g}_{k} \\
1-\frac{\bar{g}_{k-\bar{g}_{k}}}{\bar{g}_{k+1} \bar{g}_{k}} & \text { if } \bar{g}_{k} \leq \tilde{s}<\bar{g}_{k+1} \\
0 & \text { otherwise }
\end{array}\right.
$$

For the period $t+1$ the probability of next period's state to be any $\bar{g}_{k}$, and for $s^{*}$ defined by above equations, 
given any $s$ and $A$ :

$$
\tilde{\rho}_{t}\left(\bar{g}_{k} \mid s, A\right)= \begin{cases}\int_{\varepsilon \in \Omega_{k-1}}\left[\left(s^{*}-\bar{g}_{k-1}+\varepsilon\right) / d\right] d \Phi(\varepsilon)+\int_{\varepsilon \in \Omega_{k}}\left[1-\left(s^{*}-\bar{g}_{k}+\varepsilon\right) / d\right] d \Phi(\varepsilon) & \text { if } k \in(0, L) \\ \Phi\left(\bar{g}_{0}-s^{*}\right)+\int_{\varepsilon \in \Omega_{0}}\left[1-\left(s^{*}-\bar{g}_{0}+\varepsilon\right) / d\right] d \Phi(\varepsilon) & \text { if } k=0 \\ 1-\Phi\left(\bar{g}_{L}-s^{*}\right)+\int_{\varepsilon \in \Omega_{L-1}}\left[\left(s^{*}-\bar{g}_{L-1}+\varepsilon\right) / d\right] d \Phi(\varepsilon) & \text { if } k=L\end{cases}
$$

where $\Omega_{k}=\left[\bar{g}_{k}-s^{*}, \bar{g}_{k+1}-s^{*}\right)$.

\section{Existence of Optimal Advertising Solution}

Here I only consider the solution for Oblivious Equilibrium under no-dominant firms. So it is sufficient to consider only one representative firm. From equation (2), the first order necessary condition is

$$
-\left(k+\nu_{j t}\right)+\beta \cdot \sum_{k} W_{j, t+1}\left(\bar{g}_{k}\right) \frac{\partial \tilde{\rho}_{t}\left(\bar{g}_{k} \mid s, A\right)}{\partial A}=0
$$

Recall Leibniz Rule:

$$
\frac{\partial}{\partial z} \int_{a(z)}^{b(z)} f(x) d x=f(b(z)) \frac{\partial b}{\partial z}-f(a(z)) \frac{\partial a}{\partial z}
$$

Recall from above the probability transition function, let $\varphi(\cdot)$ be the pdf of $\varepsilon$ distribution then:

$$
\begin{aligned}
\frac{\partial \tilde{\rho}_{t}\left(\bar{g}_{k} \mid s, A\right)}{\partial A} & =\frac{\partial s^{*}}{\partial A} \frac{1}{d} \cdot\left[\left.\Phi(\varepsilon)\right|_{\Omega_{k-1}}-\left.\Phi(\varepsilon)\right|_{\Omega_{k}}\right] \\
& =\frac{\partial s^{*}}{\partial A} \frac{1}{d}\left[2 \Phi\left(\bar{g}_{k}-s^{*}\right)-\Phi\left(\bar{g}_{k-1}-s^{*}\right)-\Phi\left(\bar{g}_{k+1}-s^{*}\right)\right] \\
\frac{\partial \tilde{\rho}_{t}\left(\bar{g}_{0} \mid s, A\right)}{\partial A} & =-\left.\frac{\partial s^{*}}{\partial A} \frac{1}{d} \cdot \Phi(\varepsilon)\right|_{\Omega_{0}}=\frac{\partial s^{*}}{\partial A} \frac{1}{d} \cdot\left(\Phi\left(\bar{g}_{0}-s^{*}\right)-\Phi\left(\bar{g}_{1}-s^{*}\right)\right) \\
\frac{\partial \tilde{\rho}_{t}\left(\bar{g}_{L} \mid s, A\right)}{\partial A} & =\left.\frac{\partial s^{*}}{\partial A} \frac{1}{d} \cdot \Phi(\varepsilon)\right|_{\Omega_{L-1}}=\frac{\partial s^{*}}{\partial A} \frac{1}{d} \cdot\left(\Phi\left(\bar{g}_{L}-s^{*}\right)-\Phi\left(\bar{g}_{N-1}-s^{*}\right)\right)
\end{aligned}
$$

where:

$$
\frac{\partial s^{*}}{\partial A}=\frac{\theta_{t}}{\theta_{t} A+1}
$$

Check second order condition, and need: SOC of $A$ to satisfy the following to ensure concavity and solution.

$$
\beta \sum_{k} W_{j, t+1}\left(\bar{g}_{k}\right) \frac{\partial^{2} \tilde{\rho}_{t}\left(\bar{g}_{k} \mid s, A\right)}{\partial A^{2}}<0
$$

It's clear from above that:

$$
\begin{aligned}
\frac{\partial^{2} \tilde{\rho}_{t}\left(\bar{g}_{k} \mid s, A\right)}{\partial A^{2}} & =\frac{\partial^{2} s^{*}}{\partial A^{2}} \frac{1}{d}\left[2 \Phi\left(\bar{g}_{k}-s^{*}\right)-\Phi\left(\bar{g}_{k-1}-s^{*}\right)-\Phi\left(\bar{g}_{k+1}-s^{*}\right)\right] \\
& -\left(\frac{\partial s^{*}}{\partial A}\right)^{2} \frac{1}{d}\left[2 \varphi\left(\bar{g}_{k}-s^{*}\right)-\varphi\left(\bar{g}_{k-1}-s^{*}\right)-\varphi\left(\bar{g}_{k+1}-s^{*}\right)\right]
\end{aligned}
$$

Similarly define $\frac{\partial^{2} \tilde{\rho}_{t}\left(\bar{g}_{0} \mid s, A\right)}{\partial A^{2}}$ and $\frac{\partial \tilde{\rho}_{t}\left(\bar{g}_{L} \mid s, A\right)}{\partial A}$. Simplify notation a bit, let's call $\Phi\left(\bar{g}_{k}-s^{*}\right)-\Phi\left(\bar{g}_{k-1}-s^{*}\right)=\Phi_{k}$, and call $\varphi\left(\bar{g}_{k}-s^{*}\right)-\varphi\left(\bar{g}_{k-1}-s^{*}\right)=\varphi_{k}$, let the following be defined:

$$
\begin{aligned}
C m_{1} & =-W_{0} \cdot \Phi_{1}+\left(W_{1} \Phi_{1}-W_{1} \Phi_{2}\right)+\ldots+\left(W_{L-1} \Phi_{L-1}-W_{L-1} \Phi_{L}\right)+W_{L} \Phi_{L} \\
& =\left(W_{1}-W_{0}\right) \Phi_{1}+\left(W_{2}-W_{1}\right) \Phi_{2}+\ldots+\left(W_{L}-W_{L-1}\right) \Phi_{L} \\
C m_{2} & =-W_{0} \cdot \varphi_{1}+\left(W_{1} \varphi_{1}-W_{1} \varphi_{2}\right)+\ldots+\left(W_{L-1} \varphi_{L-1}-W_{L-1} \varphi_{L}\right)+W_{L} \varphi_{L} \\
& =\left(W_{1}-W_{0}\right) \varphi_{1}+\left(W_{2}-W_{1}\right) \varphi_{2}+\ldots+\left(W_{L}-W_{L-1}\right) \varphi_{L}
\end{aligned}
$$


Then, the second order condition looks like:

$$
\frac{\beta}{d} \cdot\left(\frac{\partial^{2} s^{*}}{\partial A^{2}} \cdot C m_{1}-\left(\frac{\partial s^{*}}{\partial A}\right)^{2} \cdot C m_{2}\right)
$$

By assumption that $\eta \in(0,1), W$ is concave in goodwill stock, then $W_{k}>W_{k-1}$. Due to the nature of CDF of a distribution, I know that $C m_{1}>0$. Also by assumption, I know $\frac{\partial^{2} s^{*}}{\partial A^{2}}<0$. Furthermore:

$$
\begin{aligned}
\frac{\partial^{2} s^{*}}{\partial A^{2}} & =-\frac{\theta_{t}^{2}}{\left(\theta_{t} A_{j t}+1\right)^{2}} \\
\left(\frac{\partial s^{*}}{\partial A}\right)^{2} & =\left(\frac{\theta_{t}}{\theta_{t} A_{j t}+1}\right)^{2}
\end{aligned}
$$

then it is clear that $\left|\frac{\partial^{2} s^{*}}{\partial A^{2}}\right|=\left(\frac{\partial s^{*}}{\partial A}\right)^{2}$, then it is clear that as $A$ increases, at $s=s^{*}$ the value function becomes concave. Therefore, the problem has a solution.

\section{A Myopic Example of Advertising Spending Recovery}

To illustrate the intuition behind the advertising spending recovery, consider a simple example of the model present in the paper. In this example, all firms are assumed to be myopic, or $\beta=0$; ignore both forecast error $\varepsilon$ and brand cost shock $\nu$; the number of brand is fixed at $N$ and there is no entry or exit; and assume all brands are symmetric.

I use this example to illustrate that in steady states, when advertising efficiency parameter $\theta$ decreases, three things can happen for a representative firm: (1) long run steady state goodwill stock decreases; (2) long run steady state advertising spending increases; (3) when transition from a steady state with high $\theta$ to a steady state with low $\theta$, advertising spending initially falls then recovers.

Let advertising of firm $j$ be $A_{j t}$. Let goodwill be $s_{j t}$. Suppose $s$ evolves in the following fashion:

$$
s_{j, t}=\delta s_{j t-1}+\log \left(\theta_{t} A_{j t}+1\right)
$$

Let $D s(A)$ denote the derivative of $s$ with respect to $A$, then $D s(A)=\frac{\theta}{\theta A+1}$. And assume the revenue for each individual is just its market share:

$$
R_{j}=\frac{s_{j}}{\sum_{i=1}^{J} s_{i}}=1-\frac{\sum_{i \neq j} s_{i}+1}{\sum_{i}\left(s_{i}+1\right)}
$$

The specifications above are the same as in the paper. Then, a firm $j$ in time $t$ solve the following problem:

$$
\max _{A} R_{j}(A)-A
$$

And the first order necessary condition is:

$$
D s_{j}\left(A_{j}\right) \cdot \frac{\sum_{i \neq j} s_{i}+1}{\left(\sum_{i}\left(s_{i}+1\right)\right)^{2}}-1=0
$$

Suppose that we have a symmetric equilibrium where all firms have goodwill stock level $s_{t}$ (this is possible when all firms start with the same initial state), then since the number of firms is $N$ :

$$
\frac{N-1}{N^{2}} \frac{\frac{\theta}{\theta A_{t}+1}}{s_{t}+1}-1=0
$$

Suppose in steady state, and $s_{t}=s^{*} A_{t}=A^{*}$ for all $t$, then:

$$
s^{*}=\frac{\log \left(\theta A^{*}+1\right)}{1-\delta}
$$


then the first order condition is:

$$
\frac{N-1}{N^{2}} \frac{1-\delta}{\log \left(\theta A^{*}+1\right)+(1-\delta)} \frac{\theta}{\theta A^{*}+1}-1=0
$$

The above two equations give the long run steady state goodwill stock $s^{*}$ and advertising spending $A^{*}$ as functions of advertising efficiency $\theta$. To see how $A^{*}$ changes with respect to $\theta$, I consider the elasticity term $\theta D A(\theta) / A(\theta)$. I can totally differentiate the first order condition to get this:

$$
\frac{\theta D A^{*}(\theta)}{A^{*}(\theta)}=\frac{1}{\left(1+\left[\log \left(\theta A^{*}+1\right)+(1-\delta)\right]^{-1}\right)} \frac{\theta A^{*}+1}{\theta A^{*}}-1
$$

Denote $\varsigma\left(\theta A^{*}(\theta)\right)=\left(1+\left[\log \left(\theta A^{*}+1\right)+(1-\delta)\right]^{-1}\right) \frac{\theta A^{*}}{\theta A^{*}+1}$. Notice that $\varsigma(x)=-\frac{x D^{2} R(x)}{D R(x)}$. Hence if the curvature of revenue function is large, or $\varsigma(x)>1$, then an increase in $\theta$ leads to decrease in $A^{*}$. Since the revenue function is asymptotically converging to a finite number, when $\theta$ is large enough, $\varsigma(x)>1$.

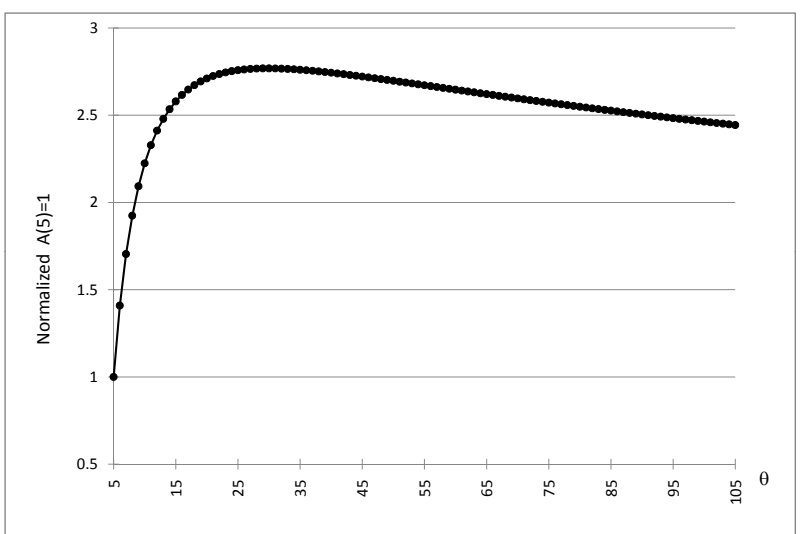

(a) Steady State Advertising $A^{*}$

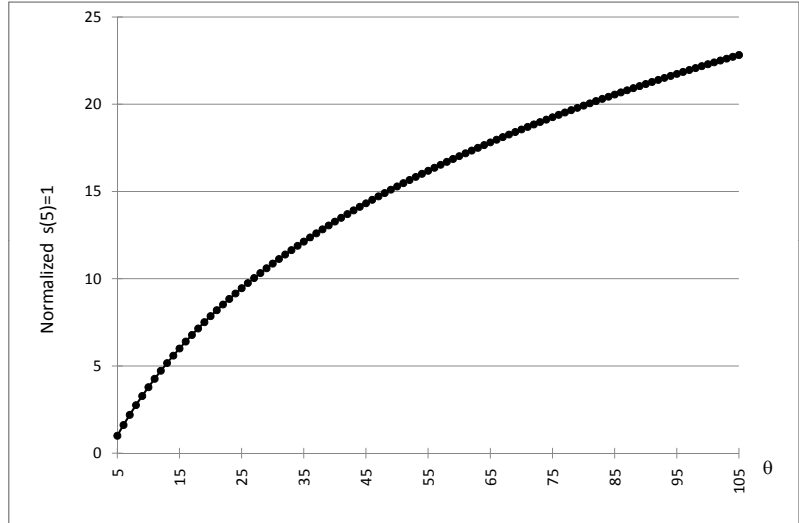

(b) Steady State Goodwill Stock $s^{*}$

Figure A.1. Simple Example: $A^{*}$ And $s^{*}$ as functions of $\theta$

Since it is difficult to get analytical results from the above expressions, I use the following numerical example to illustrate the intuition. I choose $N=3, \delta=0.8$, and let $\theta$ varying on the interval [5, 105], with grid size 1 (for a wide range of parameters, the qualitative results hold). I show functions $A^{*}(\theta)$ and $s^{*}(\theta)$ in Figure A.1. As show, as $\theta$ increases, the steady state advertising $A^{*}$ increases initially, then decreases steadily after attaining a max level around $\theta=30$. In addition, I show the steady state transition when $\theta$ is lowered from 150 to 30 in Figure A.2. Advertising spending initially drops but recovers quickly to the new steady state, which is higher than the initial

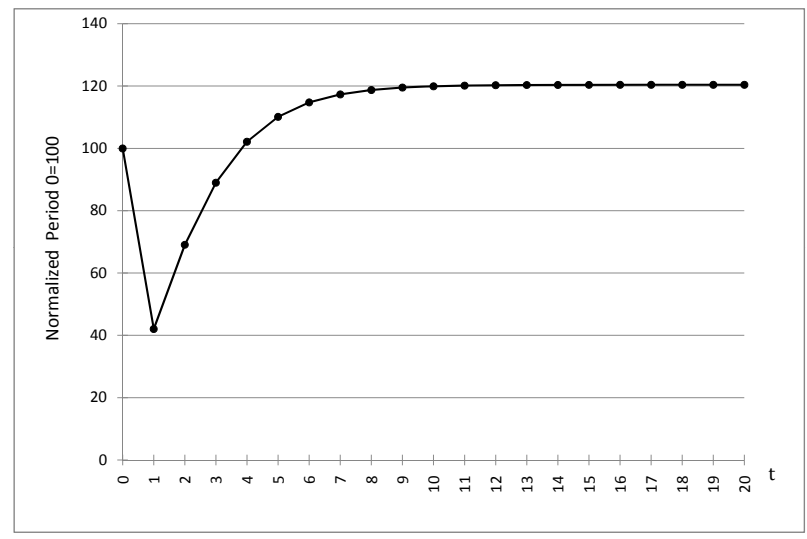

(a) Advertising $A$

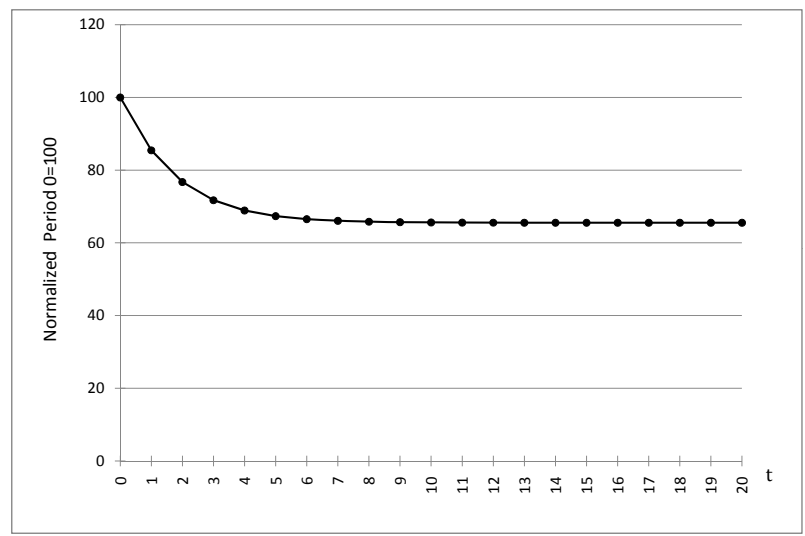

(b) Goodwill Stock $s$

Figure A.2. Simple Example: Steady State Transition

level. Meantime, we see a downward adjustment in goodwill stock level. The initial drop of advertising spending 
was due to lack of immediate change in goodwill stock level. 